\title{
Recovery of Rare Earth Elements by Carbon-Based Nanomaterials-A Review
}

\author{
Celso E. D. Cardoso ${ }^{1}{ }^{\circledR}$, Joana C. Almeida ${ }^{1}\left(\mathbb{D}\right.$, Cláudia B. Lopes $^{1}{ }^{1}$ Tito Trindade $^{1}{ }^{\circledR}$, Carlos Vale ${ }^{2}$ \\ and Eduarda Pereira ${ }^{1, *}$ \\ 1 Chemistry Department, CICECO and CESAM \& LAQV-REQUIMTE, University of Aveiro, \\ Campus de Santiago, 3810-193 Aveiro, Portugal; cedc@ua.pt (C.E.D.C.); joana.cruz.almeida@ua.pt (J.C.A.); \\ claudia.b.lopes@ua.pt (C.B.L.); tito@ua.pt (T.T.) \\ 2 Interdisciplinar Centre of Marine and Environmental Research, 4450-208 Matosinhos, Portugal; \\ carlos.vale@ciimar.up.pt \\ * Correspondence: eduper@ua.pt; Tel.: +351-234-370721
}

Received: 3 May 2019; Accepted: 21 May 2019; Published: 29 May 2019

\begin{abstract}
Modern societies depend strongly on electronic and electric equipment (EEE) which has a side effect result on the large production of electronic wastes (e-waste). This has been regarded as a worldwide issue, because of its environmental impact-namely due to non-adequate treatment and storage limitations. In particular, EEE is dependent on the availability of rare earth elements (REEs), considered as the "vitamins" of modern industry, due to their crucial role in the development of new cutting-edge technologies. High demand and limited resources of REEs in Europe, combined with potential environmental problems, enforce the development of innovative low-cost techniques and materials to recover these elements from e-waste and wastewaters. In this context, sorption methods have shown advantages to pre-concentrate REEs from wastewaters and several studies have reported the use of diverse nanomaterials for these purposes, although mostly describing the sorption of REEs from synthetic and mono-elemental solutions at unrealistic metal concentrations. This review is a one-stop-reference by bringing together recent research works in the scope of the application of carbon nanomaterials for the recovery of REEs from water.
\end{abstract}

Keywords: carbon nanostructures; E-waste; rare earth elements; solid phase extraction; sorption

\section{Introduction}

Emerging key technologies related namely to renewable energy, energy efficiency, electronics, and aerospace industries, have an important role in the current socio-economic. Environmental and public health risks are still poorly documented. Pursuing solutions to support the transition towards a sustainable lifestyle is thus crucial. In this context, the increasing use of raw material containing the designated technology-critical elements (TCEs) and the environmental impacts derived from mining to end-of-life waste products are of common concern. European Union proposed this label for the elements because there are no mining zones with an acceptable short/mid-term profit of these elements within the EU borders [1]. Activities related to the availability of those elements are hence of economic relevance. TCEs include $\mathrm{Ga}, \mathrm{Ge}, \mathrm{In}, \mathrm{Te}, \mathrm{Nb}, \mathrm{Ta}, \mathrm{Tl}$, the platinum group elements (PGEs: Pt, Pd, Rh, Os, Ir, Ru), and most of the rare earth elements (REEs: Y, $\mathrm{La}, \mathrm{Ce}, \mathrm{Pr}, \mathrm{Nd}, \mathrm{Sm}, \mathrm{Eu}, \mathrm{Gd}$, $\mathrm{Tb}, \mathrm{Dy}, \mathrm{Ho}, \mathrm{Er}, \mathrm{Yb}, \mathrm{Lu}$ ).

Currently, the extraction of TCEs from ores involves large energy costs and has potential environmental risks because of the chemicals used during mining and extraction operations [2]. An alternative source to obtain TCEs is from recycling waste electrical and electronic equipment (e-waste). However, recycling is generally expensive and shows low efficacy [3-12]. Although the use 
of TCEs is in the infancy, recent studies have reported enhanced concentrations of various REEs in waters of the Rhine River (Germany) [13] and of the San Francisco Bay (USA) [14]. TCEs can be released into the environment and become in contact with any stage of the life cycle [15]. Searching more effective technologies that respond to manifold challenges in the recovery of TCEs from Waste Electrical and Electronic Equipment (WEEE) is, therefore, an emerging and pertinent issue.

\section{Waste of Electrical and Electronic Equipment}

There are several definitions of e-waste. In this work e-waste is considered a specific form of waste that mainly covers old, end-of-life and/or discarded appliances that used electricity for working. Examples of e-wastes are highly consumed electronics (e.g., computers, Liquid-Crystal Display (LCD) screens, smartphones), large appliances (e.g., refrigerators, washers or dryers) and other similarly consumed products that are discarded by their original users or by having a manufacturing defect [16,17]. The reported quantity of e-waste generated worldwide in 2016 was 44.7 million tonnes (Mt), which correspond to $6.1 \mathrm{~kg}$ per inhabitant, and is expected to reach 52.2 million tonnes in 2021 (Figure 1).

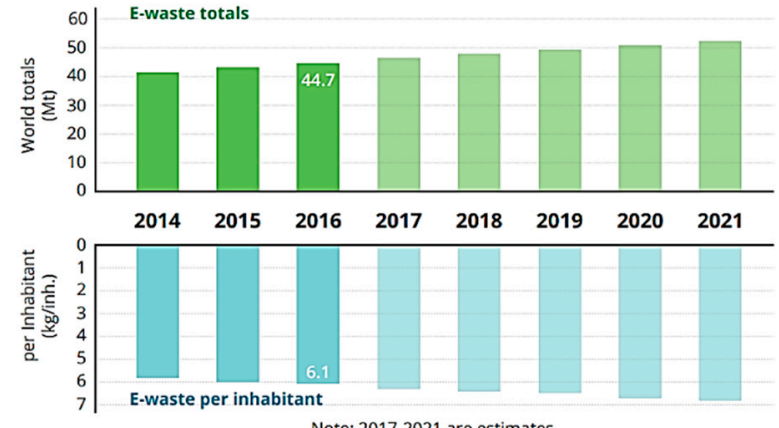

(a)

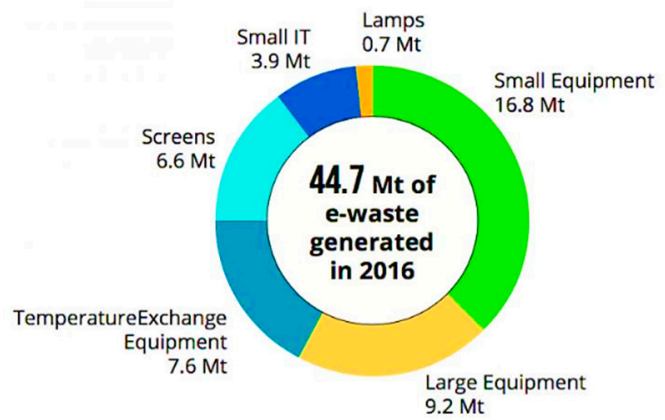

(b)

Figure 1. (a) Amount of global e-waste generated from 2014 to 2016 and values estimated for the following years (2017 to 2021) and (b) typology of e-waste produced in 2016. Adapted from Baldé et al. (2017) [18], with permission from ITU, 2017.

The economic value of raw materials containing e-waste was estimated as 55 Billion Euros in 2016 [18], and REEs recycling market in Europe is estimated to be worth 1 billion euros [19]. Although recycling has been strongly encouraged only $9 \%$ of e-waste has been collected [19], and the recycling rate of REEs is less than 1\% worldwide. A number of reasons contributed to this low value, such as the proliferation of EEE in consuming modern societies, the relatively short lifetime of products, and the complexity in TCEs recycling and recovery processes. Increase in research and development aiming at the REEs recovery technologies had little impact on the industrial sector with the exception of the recovery of REEs from lamp phosphors [17,19].

\section{Technology-Critical Elements}

Supply and demand of TCEs in high-technology, energy supply and green applications are unbalanced. Figure 2 shows in red $\mathrm{Ga}, \mathrm{Ge}, \mathrm{In}, \mathrm{Te}, \mathrm{Nb}, \mathrm{Ta}, \mathrm{Tl}$, the platinum group elements (PGEs: Pt, $\mathrm{Pd}, \mathrm{Rh}, \mathrm{Os}, \mathrm{Ir}, \mathrm{Ru}$ ), and most of the rare-earth elements (REEs: Y, La, Ce, Pr, Nd, Sm, Eu, Gd, Tb, Dy, $\mathrm{Ho}, \mathrm{Er}, \mathrm{Yb}, \mathrm{Lu}$ ) [20]. This review focus on the recovery of REE and, therefore, a brief introduction to such elements is presented below, with emphasis on the lanthanide series. 


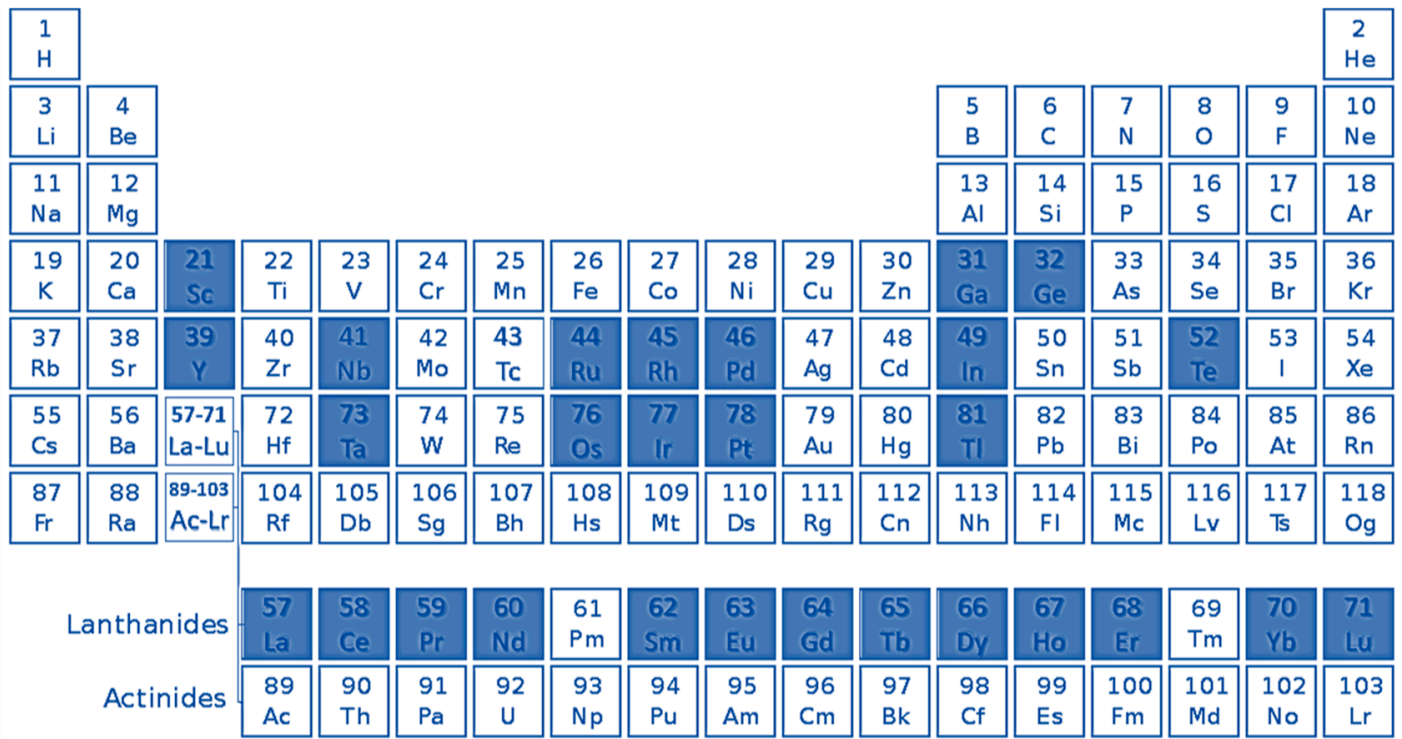

Figure 2. Periodic Table of the Chemical Elements showing in full blue squares the technology-critical elements (TCEs).

\subsection{Rare-Earth Elements: Properties and Applications}

The International Union of Pure and Applied Chemistry (IUPAC) defines the REEs as a group of 17 elements comprising the 15 lanthanoids (La to $\mathrm{Lu}$ ) plus scandium (Sc) and yttrium (Y). These two elements tend to occur in the same ore deposits as the lanthanoids and to share many chemical and physical properties [19]. REEs are usually subdivided into light REEs (LREEs), heavy REEs (HREEs) and middle REEs (MREEs), although this classification has not been consistently adopted in the literature [21]. In general, LREEs includes the elements from La to Pm, MREEs are Sm, Eu and Gd, and the elements between $\mathrm{Tb}$ and $\mathrm{Lu}$ are designated as HREEs. Yttrium is included in this group, due to a similar ionic radius and chemical properties. Scandium does not share enough similarities to be classified in any of those classes. Most of REEs occur together in mineral deposits often widely dispersed and at very low concentrations (10 to a few hundred ppm by weight). Ore mining is energy intensive process and generates large quantities of waste [22]. For example, production of 1 tonne of rare earth oxide (REO) in China generate $60,000 \mathrm{~m}^{3}$ of waste gases, $200 \mathrm{~m}^{3}$ of acidified water and 1.4 tonnes of radioactive waste since of most REEs deposits contain uranium or thorium. In addition, high energy is required, generally derived from conventional sources [23]. Figure 3 illustrates $\mathrm{Dy}, \mathrm{Tb}, \mathrm{Y}, \mathrm{Eu}$, and $\mathrm{Nd}$ [24] as critically at-risk marketable elements. Figure 4 represents the evolution of global rare earth oxides demand and supply from 2016 to 2020 [24].

In order to provide the expected increasing demand, new projects may occur for exploring and mining ores containing REEs. These elements usually are present at oxide, silicate and phosphate minerals, such as apatite, monazite or xenotime, bastnaesite and perovskites. Monazite and bastnaesite are the main minerals of LREEs and xenotime is the main source for HREEs namely Y, Dy, Ho, Er, Tm, $\mathrm{Yb}$ and $\mathrm{Lu}$ [21].

The luminescence of Lns and their compounds has been applied for a number of technological applications, that results from electronic transitions occurring within the f shell, which is well shielded inside the atom and less sensitive to the local environment. As such, for each $\mathrm{Ln}$, the luminescence spectra appear with characteristic sharp bands sharing strong similarities with the respective spectrum of the free ion. Furthermore, the luminescence lifetimes of lanthanoids are typically within the millisecond time-scale, which is superior to those observed for organic fluorophores, which might be useful for time-gate monitoring applications $[25,26]$. The luminescence of $\mathrm{Ln}^{3+}$ can be used in a wide variety of practical applications also because it covers a large spectral window depending on the Ln used, 
from the UV $\left(\mathrm{Gd}^{3+}\right)$, through the visible blue $\left(\mathrm{Tm}^{3+}\right)$, green $\left(\mathrm{Tb}^{3+}\right)$, orange $\left(\mathrm{Sm}^{3+}\right)$ and red $\left(\mathrm{Eu}^{3+}\right)$, to the near infrared (NIR) $\left(\mathrm{Pr}^{3+}, \mathrm{Nd}^{3+}, \mathrm{Er}^{3+}\right.$ and $\left.\mathrm{Yb}^{3+}\right)[25,26]$.

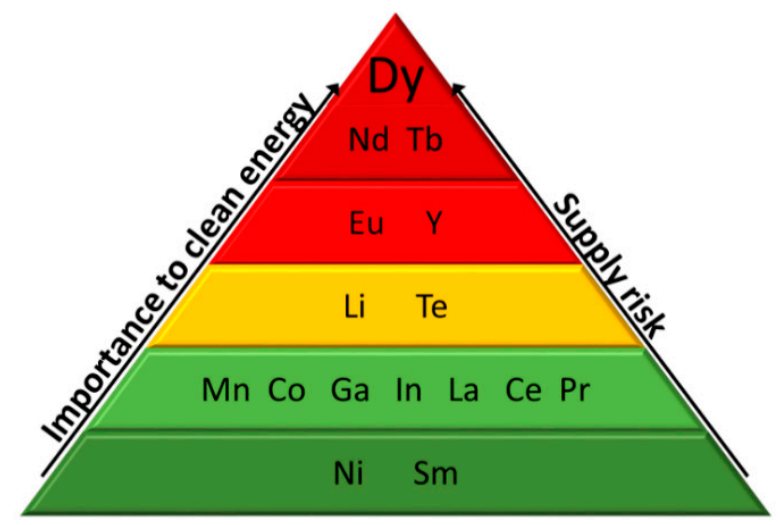

Figure 3. Criticality assessment of rare earth elements (REEs) and other elements in the medium term (2015-2025). It is represented in green the elements that are not critical, in yellow the near-critical elements and in red the critical elements.

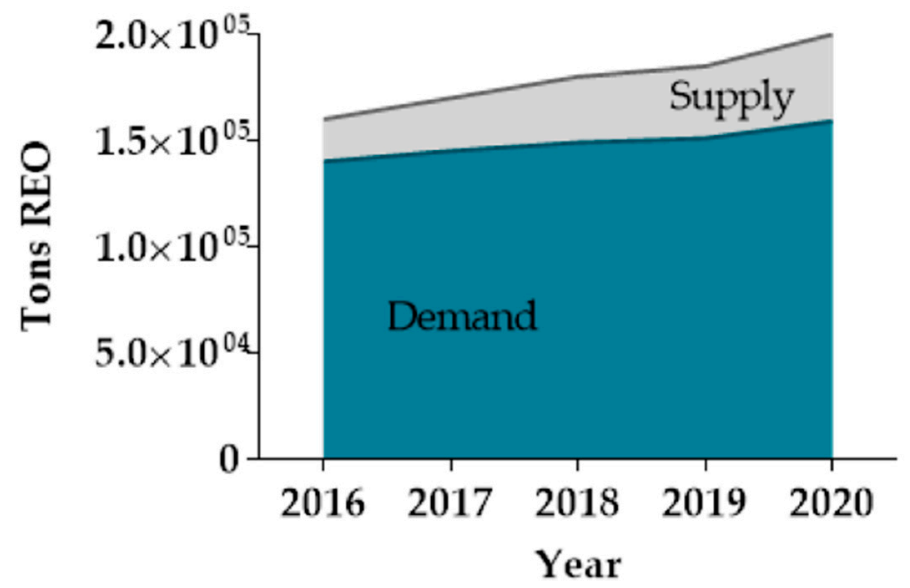

Figure 4. Evolution of global REE demand and supply from 2016 to 2020. Data obtained from [24].

\subsection{Industrial Applications of Rare Earth Elements}

Tables 1 and 2 list the application of REEs in industrial domains. In the category of LREEs, La is mainly used in fluid cracking catalysts (FCC) and batteries; it is an important element in hybrid car batteries, since acts as a hydrogen absorber in rechargeable batteries [22]; the main application of Ce is in polishing, although Ce is also used in catalytic converters for automobiles (up to 30\%), glass and metallurgy, and shows a strong affinity for elements like phosphorus, making them suitable as water purifiers; $\mathrm{Pr}$ is used in magnets and phosphors; and the $\mathrm{Nd}$ highest application are in magnets. In addition, both $\mathrm{La}$ and $\mathrm{Ce}$ act as stabilizers in catalytic compounds, such as in oil refineries. In the category of MREEs, Gd has a wide range of applications that include applications in magnets, metallurgy and phosphors industries; Sm is widely used in magnets and Eu in phosphors because of its excellent luminescent pigment properties. Finally, in the category of HREEs, Tb is used in magnets and phosphors, Er is applied in phosphor and glass industry, and the $\mathrm{Y}$ is used in ceramics and phosphors. Although generally used in small quantities, they are nonetheless essential elements in such functional devices and the technological demand for these elements will tend to increase in the future. [20,22]. 
Table 1. Overview of REEs applications and end uses.

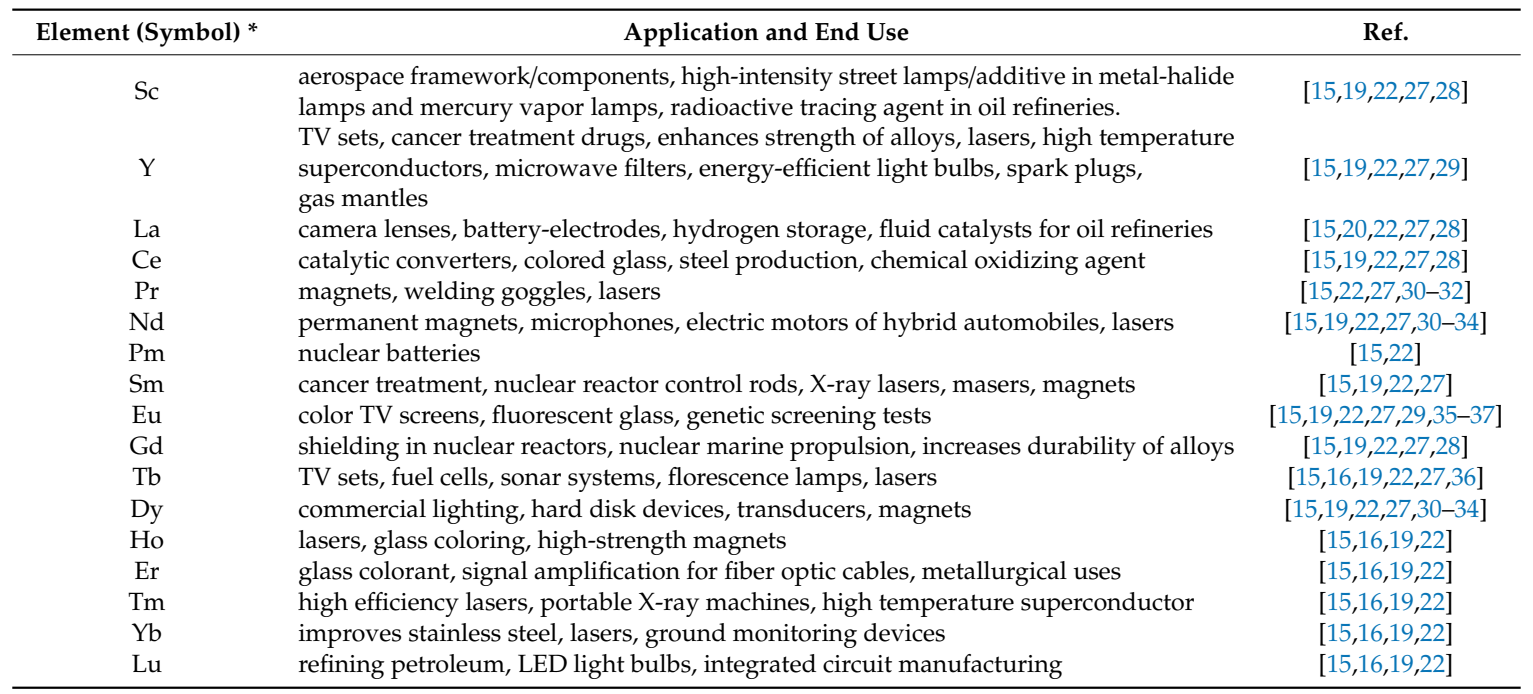

${ }^{*}$ REEs are listed in order of increasing atomic number.

Table 2. Overview of the distribution of REEs usage (in \% of rare earth oxides) in different applications, in 2012. Data source: EU report on Critical Raw Materials [20].

\begin{tabular}{|c|c|c|c|c|c|c|c|c|c|c|}
\hline REEs & Magnets & Batteries & Metallurgy & Catalysts & Polishing & Glass & Phosphors & Ceramics & Others & Total \\
\hline $\mathrm{La}$ & 0 & 26 & 10 & 45 & 1 & 5 & 1 & 1 & 9 & 100 \\
\hline $\mathrm{Ce}$ & 0 & 3 & 19 & 18 & 36 & 12 & 4 & 1 & 8 & 100 \\
\hline $\operatorname{Pr}$ & 73 & 0 & 4 & 0 & 2 & 0 & 12 & 7 & 2 & 100 \\
\hline $\mathrm{Nd}$ & 89 & 0 & 2 & 2 & 0 & 1 & 1 & 4 & 0 & 100 \\
\hline $\mathrm{Sm}$ & 97 & 0 & 0 & 0 & 0 & 0 & 0 & 0 & 3 & 100 \\
\hline $\mathrm{Eu}$ & 0 & 0 & 0 & 0 & 0 & 0 & 96 & 0 & 4 & 100 \\
\hline $\mathrm{Gd}$ & 35 & 0 & 28 & 0 & 0 & 0 & 23 & 0 & 14 & 100 \\
\hline $\mathrm{Tb}$ & 24 & 0 & 0 & 0 & 0 & 0 & 71 & 0 & 5 & 100 \\
\hline Dy & 98 & 0 & 0 & 0 & 0 & 0 & 0 & 0 & 2 & 100 \\
\hline $\mathrm{Er}$ & 0 & 0 & 0 & 0 & 0 & 72 & 25 & 0 & 3 & 100 \\
\hline $\mathrm{Y}$ & 0 & 0 & 0 & 0 & 0 & 0 & 79 & 21 & 0 & 100 \\
\hline $\begin{array}{c}\mathrm{Ho}, \mathrm{Tm}, \\
\mathrm{Yb}, \mathrm{Lu}\end{array}$ & 0 & 0 & 0 & 0 & 0 & 0 & 0 & 0 & 100 & 100 \\
\hline All REEs & 20 & 8 & 11 & 20 & 15 & 7 & 9 & 3 & 6 & 100 \\
\hline
\end{tabular}

Among the variety of REEs applications, there are four main target markets-magnets, metallurgy, catalysts and polishing powder-which account for nearly three quarters of the total use of rare earth elements in 2012. Other important applications are as pigments in glasses, phosphors and ceramics [22]. Figure 5 shows the current consumption of REEs in several applications, as well as the respective susceptibility of being replaced. REEs are particularly relevant in catalysis, phosphors, ceramics and glass industry, and difficult to replace in the case of magnets, iron and steel applications. 

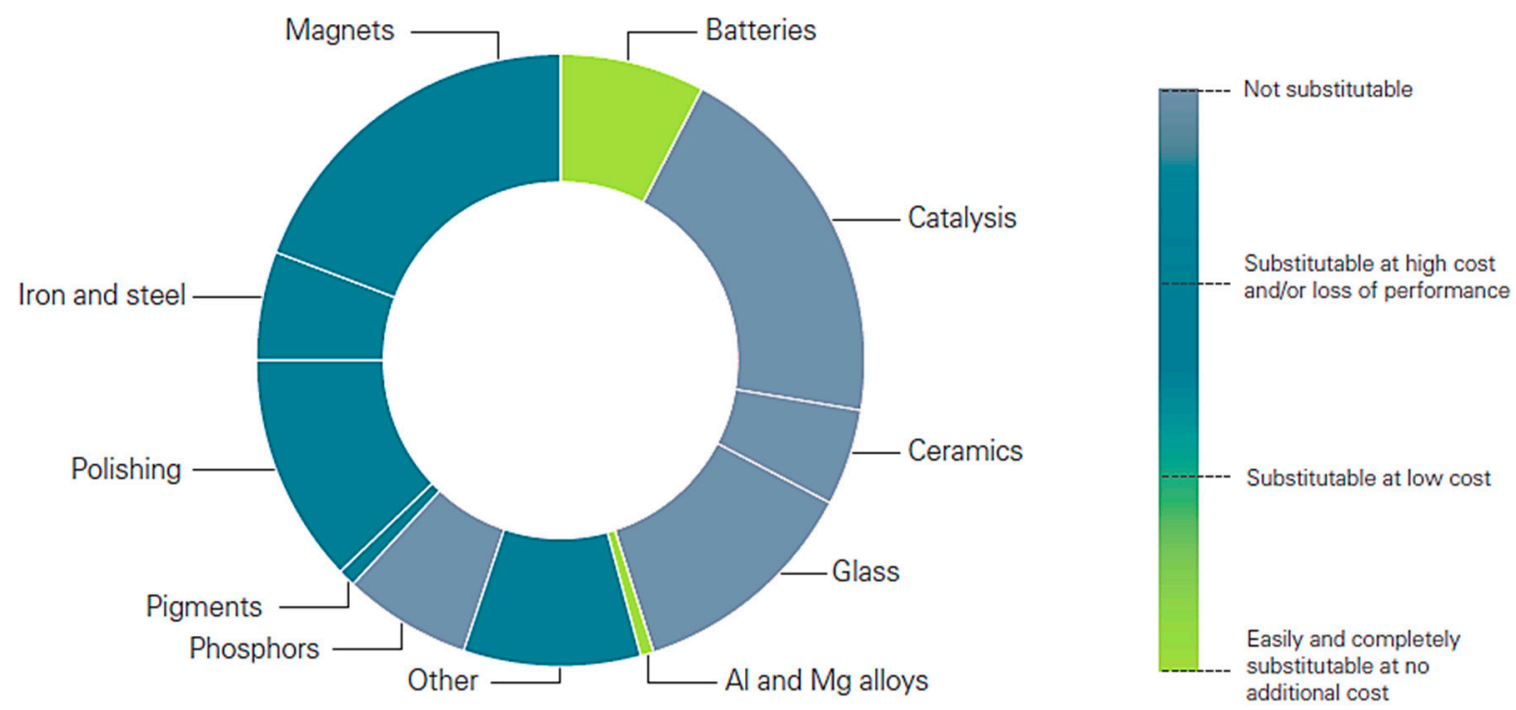

Figure 5. Current consumption of REEs in several applications, as well as the respective susceptibility to be replaced [22].

General description of the principal applications of REEs $[20,27,38]$ is as follows:

- Magnets: Many REEs have important magnetic applications, such is the case of Neodymium-Iron-Boron magnets, which also contain Pr, Dy, and Sm ions. The main applications for permanent magnets are industrial motors, hard-disc drives, hybrid and electric vehicles, and wind turbines.

- Batteries: Nickel metal hydride batteries (NiMH) are excellent for portable electronics, containing mainly La and Ce ions. NiMH batteries have also been extensively used in hybrid and electric vehicles; however, its dependence is decreasing with the growing and development of more efficient Li-ion batteries.

- Metallurgy: Light rare earth are used to improve the mechanical characteristics of alloyed steel, for desulfurization, to bind trace elements in stainless steel and in magnesium and aluminum alloys.

- Catalysts: REEs have an important role in catalysis, for example, La used in fluid catalytic cracking (FCC) in oil refineries-which increases oil refinery yields by up to $7 \%$-, and Ce in catalytic converters for cars.

- Polishing powder and glass additives: Cerium oxide is widely used as a polishing agent and as an additive in the production of glass, in the discoloration and removal of impurities.

- Phosphors: End-of-life fluorescent lamps are a rich source of heavy rare earth elements (HREEs), such as $\mathrm{Eu}, \mathrm{Tb}$ and $\mathrm{Y}$. HREEs are important constituents of tri-phase phosphor lighting used for linear fluorescent lamp tubes and compact fluorescent lamps, as well as LCD backlights for flat panel displays.

\subsection{Evidence of Anthropogenic Rare Earth in Aquatic Systems}

REEs in non-recycled waste materials may end up in surface waters and ocean. For example, the highest REEs concentration in water wells in Chinese mining areas was reported as $130 \mu \mathrm{g} / \mathrm{L}$; however, Sidaosha River - which has the highest level of REEs - has a total of REEs concentration in suspended particles and surface sediments of 31,524 and 30,461 $\mu \mathrm{g} / \mathrm{g}$, respectively [39]. Recently, high concentrations of rare earth have been detected in the surface water of San Francisco Bay [14], presumably, due to the wastewater treatment plant discharges of refractory magnetic resonance imaging (MRI) contrast agents used in hospitals and medical research centres [24]. In addition, it has been found that anthropogenic Gd contaminates surface and ground water, which highlights the need for wastewaters treatment. Indeed, wastewater can also be a source of REEs although their potential remains largely unexplored, as is the case of wastewaters produced during the extraction and separation of the elements. However, the recovery 
of REEs from acidic industrial waste water streams and mining effluents is still in its infancy, since their concentrations in industrial waste residues are very low compared to primary rare earth ores, whereby it is necessary develop special processes dedicated to the recovery of rare earth from these dilute waste streams.

\section{Recovery of Rare Earth from E-Waste}

\subsection{Recycling and Barriers to End-of-Life Recycling}

The major constraint in recycling REEs has been the low yield rate, which can be explained by the lack of adequate recycling design and by the number of steps required for their separation. These limitations have contributed to the false premise that recycling is not profitable, due to the small quantities recovered [28]. Nevertheless, several examples of REEs recovery from end-of-life products have been presented, such as from fluorescent lamps [27,29,36,37], magnets [30-34], NiMH batteries [40] and mobile phones [41]. Many of these studies report yields up to 99\% of re-usable REEs. This scenario is illustrated by the study of Kim et al. [42] on the recovery of REEs oxides (namely $\mathrm{Nd}, \operatorname{Pr}$ and Dy) from commercial $\mathrm{NdFeB}$ magnets and industrial scrap magnets by employing membrane-assisted solvent extraction and without any co-extraction of non-REEs over the $120 \mathrm{~h}$ run. Although many lab-scale experiments have reported good REEs recovery, recycling techniques in an industrial context are still in its infancy [43]. However, recently, some chemical and electrical companies are cooperating with each other, in order to develop techniques and processes to recover high purity REEs from e-waste [24]. A mature recycling route for REEs could offer a number of important advantages over primary production, such as a smaller environmental footprint (even because recycling does not leave radioactive elements to dispose of), shorter lead times and a cheaper source of material compared to primary production.

Many of the recycling techniques which are applied to the e-waste and end-of-life products, including liquid-liquid extraction processes or the use of sorbents for solid-phase extraction, either in batch or column approaches, are common for different types of products. Conversely, there are products that might be specifically treated, such as metal alloys in magnets [32,40]. It is also important to create recycling policies and networks for these products so that they can also compete-in terms of price and quality - with rare earth materials produced from primary sources. This can be accomplished by increasing the cost-efficiency and the competitiveness of dismantling, sorting, separating and re-processing of end-of-life products containing REEs and by improving the yield of various REEs recovery routes. Furthermore, strategies for preserving primary REE resources should be also implemented [28]. Regardless the recycling techniques used, several barriers need to be surpassed in order to implement recycling of REEs containing products at a large scale [22], such as: (i) Insufficient and often non-selective collection rates; (ii) Lack of information about the quantity of REE materials available for recycling; (iii) Dissipative use, since the quantity of rare earth per component or device is often very small, which can make it difficult to detect the REEs products in mixed waste streams and uneconomical to separate them; (iv) Presence of contaminants; (v) Price volatility for scrap and products like magnets or phosphors; (vi) Shipping of e-waste.

\subsection{Steps of e-Waste Treatment}

The different typology of the products containing REEs offers different challenges in the process of recovery of REEs. In a first step it is necessary that the e-waste undergo mechanical or physical treatments. At this stage, the e-waste is dismantled, separated and crushed by mechanical (shredding, cutting, grinding or milling) and by physical processes (separation by vibration, gravity, buoyancy, magnetic or Eddy current) [44]. The next step is a chemical decomposition by leaching or chemical treatment for later recovery of REEs from aqueous systems (Figure 6) [45]. 


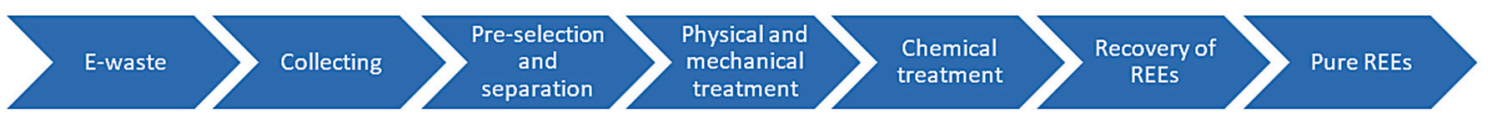

Figure 6. Steps of a general process of REEs recycling from e-waste.

It is important to note that the rare earth compounds presented in the products are intricately embedded into them-as exemplified by neodymium magnets from hard disks and compressors, electronic displays-, and are of different nature; therefore, it is recycling from consumer goods at end-of-life is usually more challenging. In this way, the recycling process needs efficient and effective physical and chemical separation techniques to be effective [46].

It is possible to observe in the literature that before starting the e-waste recycling process (namely, the recovery of the elements) there has been a pre-selection and separation of the different types of e-waste. This approach is justified by the nature, typology and constitution of e-waste that is very different from each other, whereby it offers different challenges (for example, in dismantling and treatment of e-waste) and requires more specific methods depending on the type of e-waste which it is dealing with. Even because, a common approach to e-waste treatment would become infeasible because of the way in which electronic products are produced and to the different constituents of the products. In this way it is recommended to create a "recycling line" depending on the type of end-of-life products dealing with. However, in the case of effluents, it becomes even more difficult to recover elements from the water since it has a more diversified composition. A solution might be the use of materials that are not very selective between the different rare earth, but which are between rare earth and the other elements. However, the mixture of effluents with very diverse nature could become the recovery of these elements impracticable, due to a higher entropy in the system by the elements, making the matrix too complex.

\subsection{Overview of Recovery Methodologies to Aqueous Systems}

Liquid-liquid extraction (LLE) and solid phase extraction (SPE) approaches have been applied to achieve a viable method for the separation and extraction of REEs. LLE implies two immiscible liquids (aqueous and organic solvents) to separate compounds through the attraction of the desired element from one side of the liquid phase towards another liquid phase [47]. Among the large-scale LLE techniques, there are metallurgical processes where metals are melted by heat-pyrometallurgical processes—or dissolved by a liquid—hydrometallurgical processes [45]. Pyrometallurgical techniques have commonly been used in the last three decades, due to the advantage of melting any forms of scrap [24,47]. Disadvantages are the generationally large amount of slag, loss of precious metals, and difficulty in recovery some metals [27,45]. Hydrometallurgical techniques include leaching, ion exchange, solvent extraction, and precipitation that conducts separation and extraction of metals based on the reaction in an aqueous medium. Leaching solvents commonly used are $\mathrm{H}_{2} \mathrm{SO}_{4}-\mathrm{H}_{2} \mathrm{O}_{2}$, aqua regia, thiourea, cyanide, $\mathrm{HNO}_{3}, \mathrm{NaOH}, \mathrm{HCl}$, etc. [27,45,47]. Hydrometallurgical techniques are easier to control and create less environmental hazards than the pyrometallurgical approach. However, high operating temperature and high consumption of concentrated chemicals produce a large amount of liquid wastes and toxic sludges [24,47]. Table 3 reports a few examples of studies on hydrometallurgical methods to recovery REES, as well as the references Dutta et al. [24], Kaya [45] and Hidayah and Abidin [47].

$\mathrm{SPE}$ is an extraction process of the desired element from the liquid phase towards the solid phase [47]. Among the different separation and preconcentration techniques, batch and column approaches are those that have been widely used [38]. Although LLE was more used at industrial scale, its efficiency was always questionable because of the inability to extract polar compounds, tendency to form emulsions, presence of impurities in final product, loss of extractant into aqueous phase, laborious and time-consuming, low purity of the products, and disposal of toxic or flammable chemicals [47]. In this sense, SPE offers the advantages of having a large surface area and better contact between extractant and REEs in the aqueous phase, which led to an increase of the extraction efficiency, 
selectivity, quality, contact area, and reduce chemical consumption in the separation and extraction of REEs $[57,58]$.

Table 3. The use of hydrometallurgical methods for the recovery of REEs from end-of-life products, according to the studies published in 2016 [24].

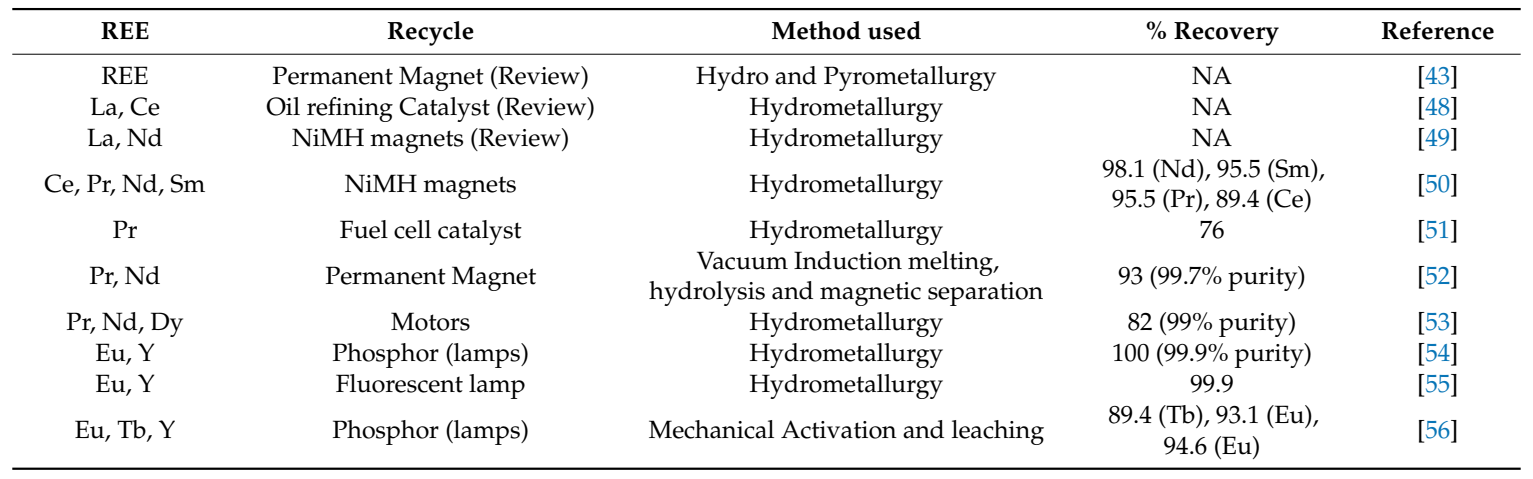

\subsubsection{Preconcentration Methods-Solid-Phase Extraction}

In general, a preconcentration method should be fully validated, efficient, rapid, use a low volume, or ideally, no harmful solvents neither require a large volume of sample [59]. When compared to LLE, the solid phase extraction offers a number of important advantages, such as reduced organic solvents usage and exposure, high enrichment factor, rapid phase separation and the possibility of combination with different detection techniques [38].

There are two basic approaches that can be recognized in SPE, namely column (or online) and batch (or offline) procedures. In the column approach, operations run out automatically, leading to a high sample throughput with lower prone to airborne sample contamination. Automation enables the analyst to undertake other tasks during the analysis of the samples and decreases the possibility of human error during the preparation; moreover, the conditions obtained are reproductible. It should be noted that a high enhancement factor does not represent an effective preconcentration. Although preconcentration efficiency depends on the time that the sample passes through the column, the enrichment can be improved by the use of a longer loading time or a higher flow rate. However, this leads to a decrease in the sampling rate [38,59]. In batch preconcentration procedures, the retention medium is mixed with the liquid sample, then filtered, and finally, the enriched phase is transferred to the detector. All these operations occur manually. Several nanomaterials have been investigated as solid phase sorbents in batch technique, such as polymers supports, carbon-based composites (carbon nanotubes and graphene oxide) and nanoparticles (NPs) in particular those exhibiting magnetic properties [60-62].

Ion imprinted polymers. Ion imprinted polymers (IIPs) are highly crosslinked polymers, which have specific binding sites for a particular metal ion. The process consists in making a template (the print metal ion on its complex) by coupling chemically with one or several functional monomers and then spatially attaching in a solid polymer by the polymerization reaction. After the imprint ion removal, the polymer with the template is obtained. This structure is complementary-in size, shape and functionality - to the ion removed, whereby it will have high selectivity to the ion. This approach is a big advantage in very specific applications that require extremely selectivity to separate elements with very similar chemistry. The interactions between the polymer framework and the complexed ion are based on coordinative bonds from some electron donating heteroatoms (such as oxygen, nitrogen or sulphur) to the unfilled orbitals of the outer sphere of the metal ions. IIPs are mainly prepared by free radical polymerization where vinyl groups are the classic type of polymerizable functions. The used ligands act as bifunctional reagents and their functionality comes both from the chelating ability and the vinyl function [38]. An alternative method for IIPs preparation is by trapping of a non-functionalized ligand inside the polymer network; these different ways of incorporating the ligands have been presented in detail in recent reviews $[63,64]$. 
Silica-based supports. Silica-based materials are good sorbents, due to their porous structure, mechanical properties, physical and chemical stability, convenient preparation, high thermal stability, high acidic stability, simple chemical synthesis, and the possibility to immobilized various functional groups on its surface to enhance the sorption to metal ions. Silica has some drawbacks, such as easy degradation at high $\mathrm{pH}$ values and difficulties to separate the sorbents from water under continuous industrial operation $[38,47,59]$.

Membrane supports. Membrane supports as polytetrafluoroethylene, polyviylidene fluoride, polyamide, and ceramic membranes are common supporting material used in solid phase extraction of REEs. The main advantage of using membranes in the extraction process is the low consumption of energy, high selectivity on REEs, low cost operation, and the easy to manage $[38,47,59]$.

Microorganism materials. Microorganisms, such as Bacillus subtilis, Escherichia coli, Pseudomonas fluorescens, Paracoccus denitrificans, Schwanella putrefaciens, and Alcaligenes faecalis are efficient and environmentally friendly sorbents in the extraction of metal ions. Another advantage of its use is the low use of expensive and toxic reagents. The microorganisms can interact with metal ions through surface adsorption, adsorption on extracellular biopolymer, biologic absorption, and adsorption on extracellular bio-mineral; however, surface adsorption is the more effective process in the REEs extraction $[38,47,59]$.

\subsubsection{Sorption a Promising Process to Recover Rare Earth Elements}

As already mentioned, various materials can be used as sorbents for the REEs recovery. Also, sorption has many other advantages when compared to the most common techniques, namely high removal efficiency, easy to operate and install, and involve low maintenance costs. Nevertheless, the efficiency of the whole process is dependent on factors that may influence the REEs recovery, either the kinetics or the sorption capacity. These factors are the typology of the sorbent and the metal ion to be recovered, as well as the experimental parameters, such as:

- $\mathrm{pH}$ of the batch, because it will affect the metal ions and the sorbent; the surface charge of the sorbents depends on the acidity of the surrounding electrolyte; since the sorption of REEs occur mainly by electrostatic forces, the surface charge of the sorbents needs to be negative;

- Temperature, because inadequate temperatures can decrease the efficiency of the sorption process;

- Dose of sorbent, since theoretically recovery rate increases with the dose;

- REE initial concentration because, for the same dose of sorbent, higher values of concentration, lead to lower sorption rates;

- Stirring speed, which controls the dispersion of particles and the mass transfer rate.

Besides these, the presence of other metal ion species, which is the realistic condition in real effluents, can influence the recovery of REEs due to the competition for the binding site. Therefore, these factors should be considered for the efficient recovery of REEs. Further discussion of this issue is in the Section 4.3.3-A3, B2 and C1.

\subsubsection{Carbon-Based Nanomaterials Applied in Solid Phase Extraction}

Recently, increasing attention has been given to carbon nanostructure materials applied in solid phase extraction. Carbon is the essential building block in many of the compounds and materials, due to its capability of having several oxidation states and/or coordination numbers. This makes carbon one of the few elements to have multiple numbers of allotropic forms like graphite, graphene, graphene oxide, carbon nanotubes, carbon nanofibers, carbon dots, among others (Figure 7). The structures of their surface are highly complex and depend on the raw materials, as well as on the production method and pre-treatment process. The sorption of REEs is mainly controlled by electrostatic forces, which are related to the various surface functional groups (O donors). Furthermore, the oxidation of the carbon surfaces provides a more hydrophilic surface and a larger number of oxygen-containing functional 
groups, such as hydroxyl, carbonyl and carboxyl groups. This variety increases the possibility of further modification and functionalization of the graphitic surface [38].

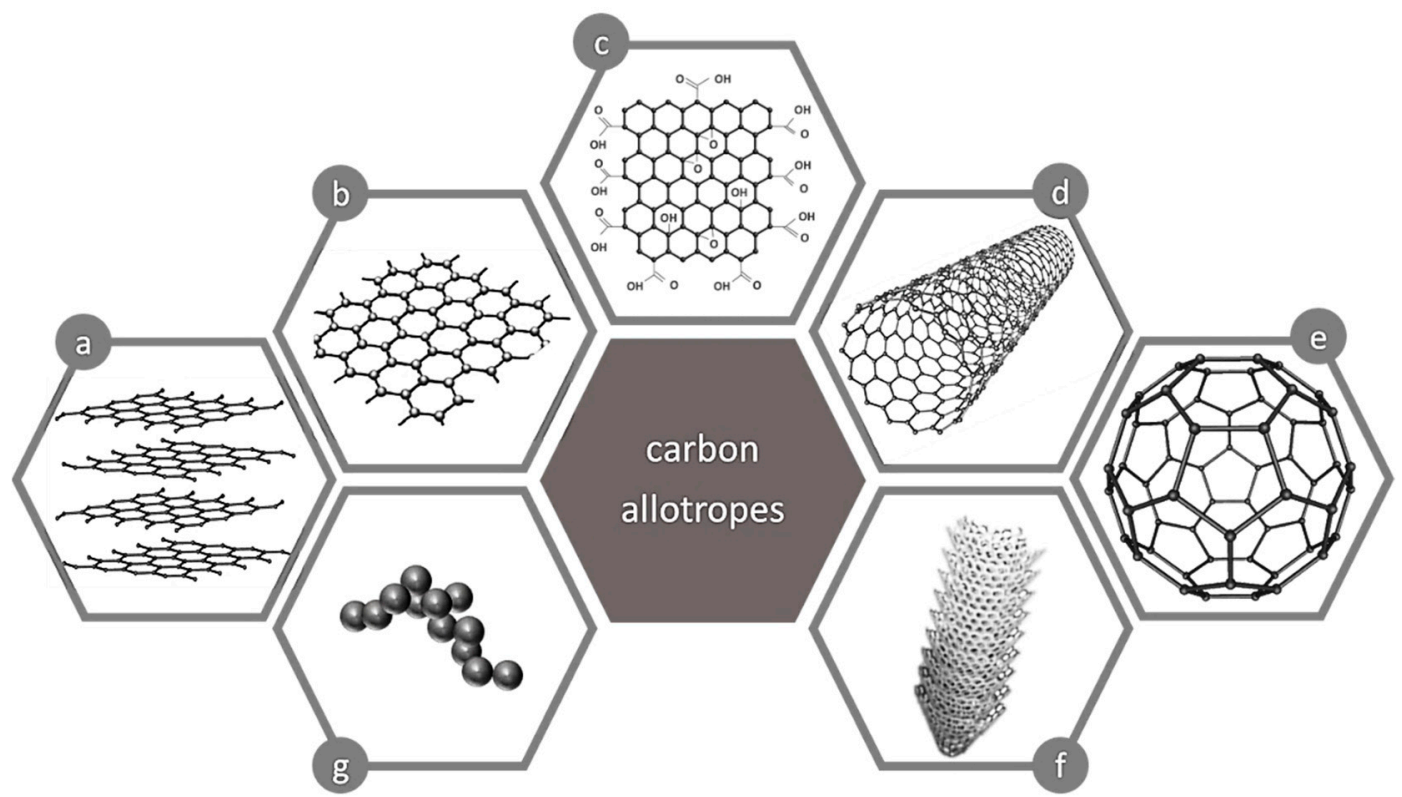

Figure 7. Carbon allotropic forms: (a) Graphite, (b) graphene, (c) graphene oxide, (d) carbon nanotube, (e) fullerene, (f) carbon nanofibers, (g) carbon dot.

A. Graphene and Graphene Oxide

Graphene is a two-dimensional material composed of covalently linked $\mathrm{sp}^{2}$ hybridized $\mathrm{C}$ atoms and that has gained high attention, due to its properties, such as high electronic conductivity, good thermal stability, excellent mechanical strength and mainly large surface area (for analytical applications). A significant advantage of graphene-based materials over carbon nanotubes (CNTs) is that for certain applications can be produced from graphite, which is a common and cheap material, without using metal catalysts. [65,66]. Nonetheless, other preparative methods are required for high quality applications, such as in electronics.

Graphene oxide (GO), mainly composed of carbon, oxygen, and hydrogen atoms, is a graphene-based material whose structure differs from the graphene structure in their regions with aliphatic six-membered rings containing hydroxyl, epoxide, carbonyl and carboxyl groups (beyond the aromatic regions with unoxidized benzene rings). Additionally, these oxygen-containing functional groups provide important nucleation sites for further chemical modification, such as decoration and functionalization. Those possibilities make GO a good candidate for usage in polymer composites, energy-related materials and sensors. GO has a high potential for removal of metal ions, due to its extremely hydrophilic properties and the presence of functional groups containing oxygen atoms. However, in water GO surface changes resulting often in an agglomeration and precipitation, due to the neutralization of negatively charged functional groups and the creation of GO-metal complexes $[67,68]$.

\section{A1-Production of Graphene and Graphene Oxide}

Graphene can be synthesized by two approaches: bottom-up and top-down. The bottom-up approach consists of conventional techniques in which a carbonaceous gas source is used to synthesize graphene. Several processes have been developed to synthesize graphene by this approach, such as electric arc, chemical conversion, $\mathrm{CO}$ reduction, CNT decompression and others [65]. However, of all processes reported in the literature, only chemical vapor deposition (CVD) and epitaxial growth appear to be attractive for the large-scale production of graphene. The top-down approach is based on an attack of bulk 
materials like graphite to break down its layers to form graphene sheets. Examples of the methods are micromechanical cleavage [69], exfoliation of graphite intercalated compounds (GIC) [70], solvent-base exfoliation, unzipping carbon nanotubes, and exfoliation or reduction of graphene oxide. This approach may be cost efficient although being limited to a lab scale and has limitations on quality control; also, it involves elevated investment and produces relatively low yields. Hence industries still search for economically favorable mass scale-up processes.

Graphite oxide can be synthesized by different methods, such as Brodie, Staudenmaier, or by Hummers method or improved Hummers method [71]. Major differences among all these methods are summarized in Table 4. The improved Hummers method has the lowest toxicity and several advantages with regard to the synthesized product [71].

Table 4. List of the advantages and disadvantages of different synthesis methods for graphite oxide. Data source: [71].

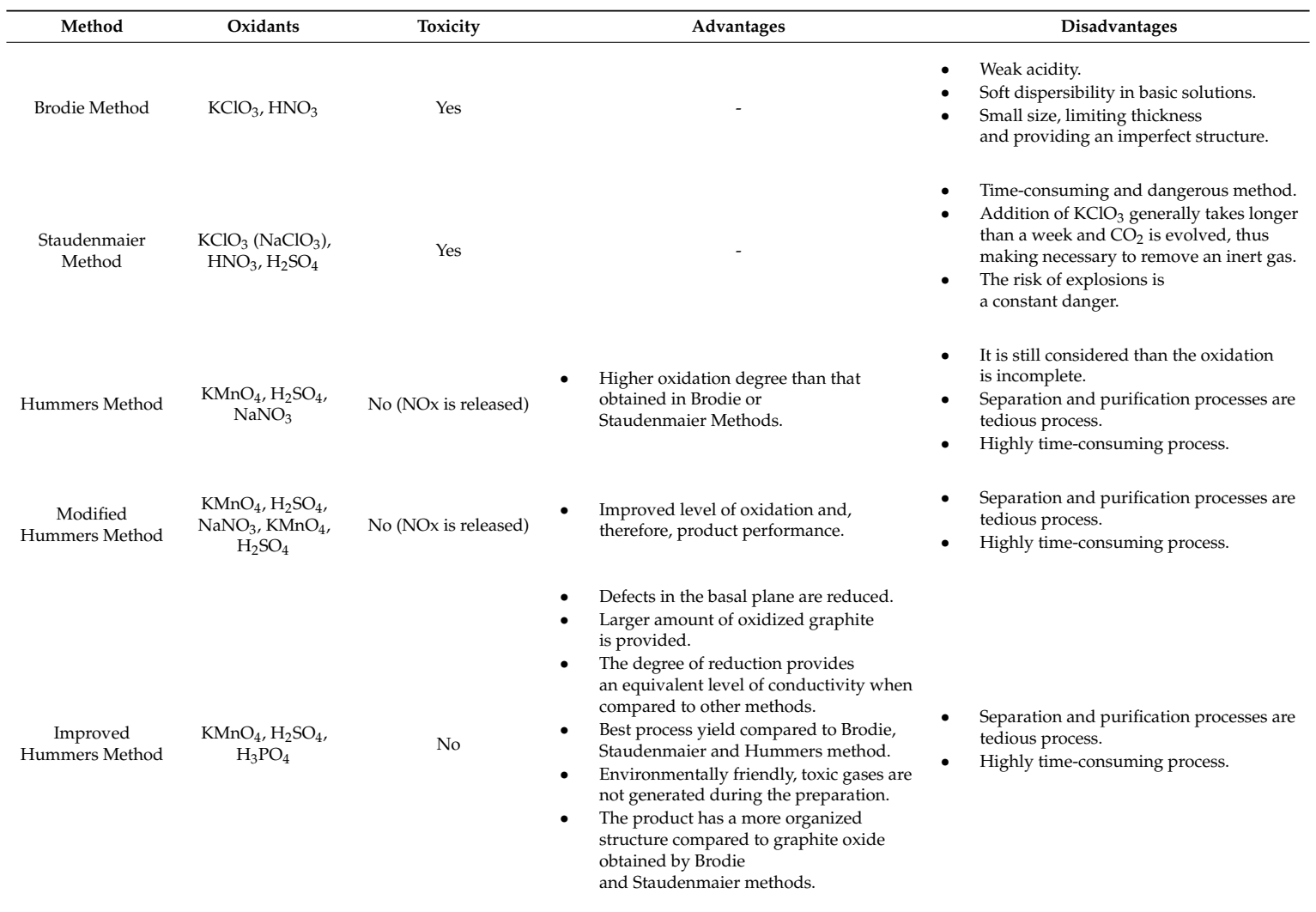

The general route to prepare GO involves two main steps (Figure 8): Firstly, graphite powder is oxidized to produce graphite oxide, and secondly, the bulk graphite oxide is exfoliated by sonication to form colloidal suspensions of monolayer, bilayer or few-layer GO sheets in different solvents [72]. Finally, solid GO can be recovered by drying the dispersion either in vacuum or atmospheric pressure at room temperature, freeze drying or at medium temperatures $\left(50\right.$ and $65^{\circ} \mathrm{C}$ ) to prevent the thermal decomposition of GO. In the preparation of GO, the critical step is the selection of suitable oxidizing agents to oxidize graphite.

Several modifications based on the Hummers method have been proposed. For example, Kovtyukhova [73] added a pre-oxidized procedure using $\mathrm{H}_{2} \mathrm{SO}_{4}, \mathrm{~K}_{2} \mathrm{~S}_{2} \mathrm{O}_{8}$, and $\mathrm{P}_{2} \mathrm{O}_{5}$. The C/O ratio of the resultant oxidation product was 4.0/3.1, which was richer in oxygen than the graphite oxide prepared by the Hummers method. This method was defined as a typical modified Hummers method and has been cited by many researchers in recent years [74-76]. The improved Hummers method was proposed by Marcano [77]. By using $\mathrm{KMnO}_{4}, \mathrm{H}_{2} \mathrm{SO}_{4}$, and $\mathrm{H}_{3} \mathrm{PO}_{4}$ as the oxidizing agents, this method 
avoids the release of $\mathrm{NO}_{\mathrm{x}}$ and produces a greater amount of hydrophilic oxidized graphite when compared to the original Hummers method [78].
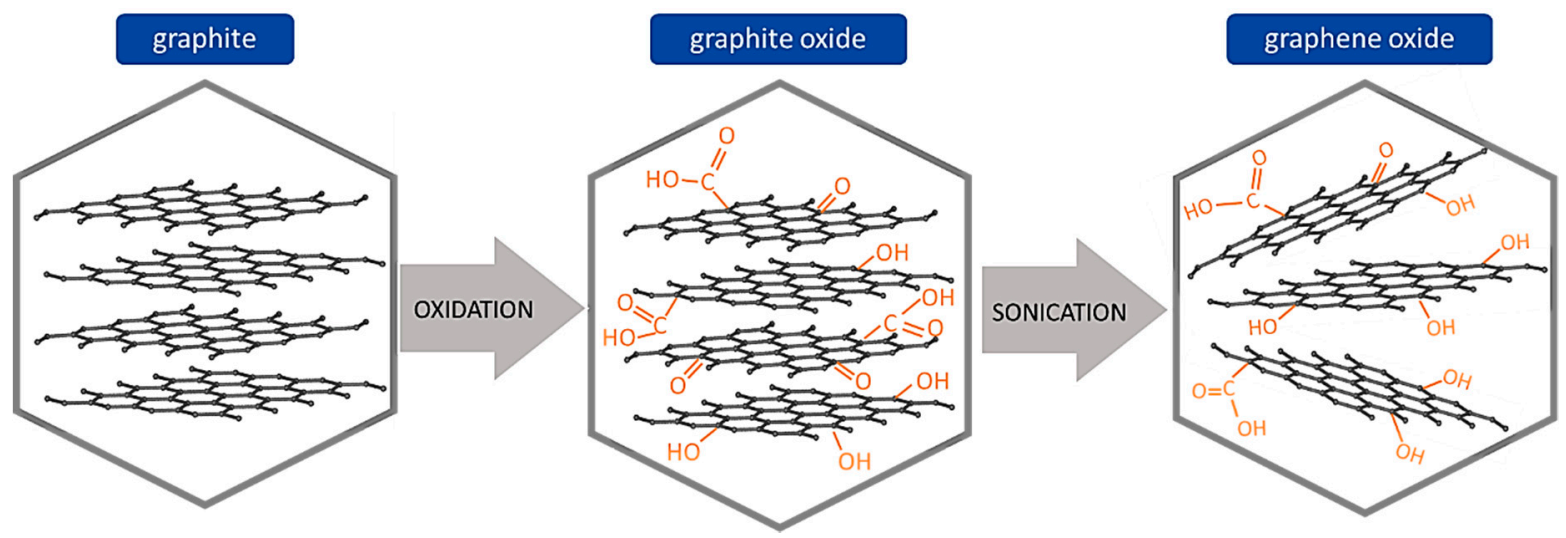

Figure 8. Representation of the general graphene oxide synthesis.

In the case of graphene oxides, it is possible to obtain different surfaces material only use different methods of synthesis, since different methods lead to different ratios of $\mathrm{C}: \mathrm{O}$ and different groups of oxygen $[68,71,79-81]$.

\section{A2-Functionalizations}

REEs show a high affinity to $\mathrm{O}$ donors and although the graphene oxide displays good adsorption properties, due to its O-based surface functional group, in more complex aqueous environments it loses efficiency. In this context, a variety of methods for the graphene surface modification have been developed in order to give new properties to the material and to improve sorption efficiency. The functionalization plays a very important role, since it determines the material surface, and consequently the point zero charge (PZC) and the $\mathrm{pH}$ used in the batch experiments. Several ligands have been applied to REEs recovery with nanomaterials, such as ferrites NPs, and silica NPs. Ethylenediaminetetraacetic acid (EDTA) [82,83] diethylenetriaminepentaacetic acid (DTPA) [84], diglycolamic acid (DGA) [85-87], humic acids [88] and others chelating ligands [89] have been applied to carbon-based nanomaterials. These functionalizations can be achieved through the preparation of nanostructured silica-coated magnetite, followed by coating with the proposed functions. The resulting material tends to display higher sorption capacity of REEs and magnetic properties that simplify the separation process of the material in aqueous media.

\section{A3-Recovery of Rare Earth Elements Using Graphene-Based Composites}

Several articles describe the use of carbon nanocomposites for the recovery of REEs, either in batch or column experiments. Table 5 summarizes the recovery of REEs by GO nanocomposites, optimal experimental conditions being represented by shading. Almost all the studies were performed in Milli-Q water with the exception of Sun et al. [90] that used $\mathrm{HClO}_{4}$ (aq, $0.01 \mathrm{~mol} / \mathrm{L}$ ). This means that only conditions with no competitive ions were tested. Despite the numerous studies at different contact time between the nanomaterial and the rare earth solution, there are no published studies over $48 \mathrm{~h}$. Most of the reported studies were performed at room temperature, although studies at higher temperature point to better rates of rare earth sorption.

A set of materials based on graphene oxide with different $\mathrm{C}: \mathrm{O}$ ratios were collected. In addition to the GO, several functionalizations were performed to make the material more efficient, such as: Magnetite $\left(\mathrm{Fe}_{3} \mathrm{O}_{4}\right)$ [91] with the purpose of affording magnetic properties to the material, making it more efficient for the REEs separation from solution, or polyaniline (PANI) [90] to increase the maximum adsorption capacity of the material. It is possible to find in the literature ratios mass of sorbent per volume of solution between the minimum of $40 \mathrm{mg} / \mathrm{L}$ and the maximum of $5000 \mathrm{mg} / \mathrm{L}$, being $1000 \mathrm{mg} / \mathrm{L}$ 
the one most reported in the literature. The studies of Chen et al. [92] and W. B. Chen et al. [93] were the ones that reported the lowest value of sorbent mass/volume $(40 \mathrm{mg} / \mathrm{L})$, which was used in the recovery of $\mathrm{Gd}(\mathrm{III})$ and $\mathrm{Y}(\mathrm{III})$ ions, respectively, at $\mathrm{pH} 5.9 \pm 0.1$.

Most studies use mono-elemental systems and only Ashour et al. [94] and Su et al. [95] reported data from a multi-elemental system. Europium is the most studied element, although Cerium was reported by Fakhri et al. [96] and Farzin et al. [97], and Gadolinium, Scandium and Yttrium by W. Chen et al. [93], Kilian et al. [98] and W. B. Chen et al. [93], respectively. Ashour et al. [94] used a quaternary system with Lanthanum, Neodymium, Gadolinium and Yttrium; and Su et al. [95] studied a mixture of fifteen REEs. A wide variety of intervals of REE concentrations were used, between $10 \mu \mathrm{g} / \mathrm{L}$ [99] and 300,000 $\mu \mathrm{g} / \mathrm{L}$ [98] were used, although the majority of the values were within 10,000-100,000 $\mu \mathrm{g} / \mathrm{L}[90-94,96,100,101]$. Lower concentrations, 10 and $50 \mu \mathrm{g} / \mathrm{L}$ of $\mathrm{Eu}(\mathrm{IIII})$ and $\mathrm{Ce}(\mathrm{III})$ ions were reported in Xie et al. [99] and Farzin et al. [97], respectively; moreover, Su et al. [95] used $10 \mu \mathrm{g} / \mathrm{L}$ for 15 elements in multi-elemental solution. Rare earth sorption is strongly $\mathrm{pH}$ dependent. In this way, several authors have tested $\mathrm{pH}$ between 2 and11 in order to search the optimal pH. The most used working $\mathrm{pH}$ is 6 [92-94,96,101]; the lowest $\mathrm{pH}$ was $2[98,101]$ and the highest one was 7 [91,101,102]. A clear example that evidences this $\mathrm{pH}$ dependence on REEs sorption is the study of $\mathrm{Li}$ et al. [102] in which Eu(III) sorption by GO and Titanium phosphate modified GO composite (GTiP-2) varied from $7-10 \%$ at $\mathrm{pH}=1,20-50 \%$ at $\mathrm{pH}=3.7$ and 5 , respectively, and $28-80 \%$ at $\mathrm{pH}=7.3$. At least two studies in the literature have reported achieving adsorption rates of approximately $100 \%$ using a pH of 5.5 [100] and 7 [101]. Finally, the material with the highest maximum adsorption capacity (qm) of REEs reported in the literature to date was PANI@GO with 250.74 mg/g achieved [90]. 
Table 5. Recovery of REEs using Graphene oxide (GO) composites and the respectively experimental conditions used as reported in the literature.

\begin{tabular}{|c|c|c|c|c|c|c|c|c|c|c|}
\hline $\begin{array}{l}\text { Ref., } \\
\text { Year }\end{array}$ & Sorbent & Type of Water & Type of System & REEs (III) & $\begin{array}{c}{[\mathrm{REEs}]_{0}} \\
(\mu \mathrm{g} / \mathrm{L})\end{array}$ & $\mathrm{pH}$ & $\mathrm{T}\left({ }^{\circ} \mathrm{C}\right)$ & $\begin{array}{c}\text { Time of } \\
\text { Contact (h) }\end{array}$ & $\begin{array}{c}\mathrm{m}(\text { Sorbent)/ } \\
\mathrm{V}(\text { Solution) }(\mathrm{mg} / \mathrm{L})\end{array}$ & $\begin{array}{c}\mathrm{q}_{\mathrm{m}}(\mathrm{mg} / \mathrm{g}) \text { or } \\
\text { REEs Adsorption (\% }\end{array}$ \\
\hline $\begin{array}{l}{[94],} \\
2017\end{array}$ & GO colloid & Ultrapure & Multi elements & $\mathrm{La}, \mathrm{Nd}, \mathrm{Gd}, \mathrm{Y}$ & $5 \times 10^{3}$ & 6 & r.t. & 0.5 & $10 \times 10^{2}$ & $\begin{aligned} \mathrm{La} & =85.7 \mathrm{mg} / \mathrm{g} \\
\mathrm{Nd} & =189 \mathrm{mg} / \mathrm{g} \\
\mathrm{Gd} & =226 \mathrm{mg} / \mathrm{g} \\
\mathrm{Y} & =136 \mathrm{mg} / \mathrm{g}\end{aligned}$ \\
\hline $\begin{array}{l}{[95],} \\
2017\end{array}$ & GO colloid & Ultrapure & Multi elements & $\mathrm{La}, \mathrm{Nd}, \mathrm{Gd}, \mathrm{Y}$ & $\begin{array}{l}(5-50) \\
10^{3}\end{array}$ & $3-8$ & $5-45$ & $0.02-2$ & $10 \times 10^{2}$ & \\
\hline $\begin{array}{l}{[91],} \\
2015\end{array}$ & GO & Ultrapure & Mono element & $\mathrm{Eu}$ & $\begin{array}{c}10 \times 10^{3} \\
\mathrm{NaClO}_{4}=0.01 \mathrm{~mol} / \mathrm{L}\end{array}$ & $\begin{array}{l}4.5, \\
7\end{array}$ & 20 & $0-24$ & $10 \times 10^{2}$ & $\begin{array}{c}90 \% \\
89.7 \mathrm{mg} / \mathrm{g}\end{array}$ \\
\hline $\begin{array}{l}{[92],} \\
2015\end{array}$ & MGO & Ultrapure & Mono element & $\mathrm{Eu}$ & $\begin{array}{c}10 \times 10^{3} \\
\mathrm{NaClO}_{4}=0.01 \mathrm{~mol} / \mathrm{L}\end{array}$ & $\begin{array}{l}4.5 \\
7\end{array}$ & 20 & $0-24$ & $10 \times 10^{2}$ & $\begin{array}{c}80 \% \\
70.2 \mathrm{mg} / \mathrm{g}\end{array}$ \\
\hline $\begin{array}{l}{[101],} \\
2012\end{array}$ & GONS & Ultrapure & Mono element & $\mathrm{Eu}^{(1)}$ & $\begin{array}{c}51 \times 10^{3} \\
\mathrm{NaClO}_{4}=0.01 \mathrm{~mol} / \mathrm{L}\end{array}$ & $\begin{array}{c}2 \\
4.5 \\
6 \\
7\end{array}$ & 25 & 48 & $2 \times 10^{2}$ & $\begin{array}{c}65 \%, 167.16 \mathrm{mg} / \mathrm{g} \\
161.29 \mathrm{mg} / \mathrm{g} \\
175.44 \mathrm{mg} / \mathrm{g} \\
100 \%\end{array}$ \\
\hline $\begin{array}{l}{[101],} \\
2012\end{array}$ & GONS & Ultrapure & Mono element & $\mathrm{Eu}$ & $\begin{array}{c}51 \times 10^{3} \\
\mathrm{NaClO}_{4}=0.01 \mathrm{~mol} / \mathrm{L}\end{array}$ & $2-11$ & $25,45,65$ & 48 & $2 \times 10^{2}$ & \\
\hline $\begin{array}{l}{[100],} \\
2016\end{array}$ & GO & Ultrapure & Mono element & $\mathrm{Eu}$ & $\begin{array}{c}10 \times 10^{3} \\
\mathrm{NaCl}=0.1,0.01,0.001 \\
\mathrm{~mol} / \mathrm{L}\end{array}$ & 5.5 & 20 & $0-24$ & $5 \times 10^{2}$ & $100 \%, 143 \mathrm{mg} / \mathrm{g}$ \\
\hline $\begin{array}{l}{[100],} \\
2016\end{array}$ & $\mathrm{GO}-\mathrm{OSO}_{3} \mathrm{H}$ & Ultrapure & Mono element & $\mathrm{Eu}$ & $\begin{array}{c}10 \times 10^{3} \\
\mathrm{NaCl}=0.1,0.01,0.001 \\
\mathrm{~mol} / \mathrm{L}\end{array}$ & 5.5 & 20 & $0-24$ & $5 \times 10^{2}$ & $90 \%, 125 \mathrm{mg} / \mathrm{g}$ \\
\hline $\begin{array}{l}{[100],} \\
2016\end{array}$ & $\begin{array}{c}\mathrm{GOe} \\
\mathrm{GO}^{-\mathrm{OSO}_{3} \mathrm{H}}\end{array}$ & Ultrapure & Mono element & $\mathrm{Eu}$ & $\begin{array}{c}10 \times 10^{3} \\
\mathrm{NaCl}=0.1,0.01,0.001 \\
\mathrm{~mol} / \mathrm{L}\end{array}$ & $1-11$ & 20 & $0-24$ & $5 \times 10^{2}$ & \\
\hline $\begin{array}{l}{[92],} \\
2014\end{array}$ & GO colloid & Ultrapure & Mono element & $\mathrm{Gd}$ & $12 \times 10^{3}$ & $\begin{array}{c}5.9 \\
(2-11)\end{array}$ & 30 & 0.5 & $0.4 \times 10^{2}$ & $287 \mathrm{mg} / \mathrm{g}$ \\
\hline $\begin{array}{l}{[93]} \\
2014\end{array}$ & GO colloid & Ultrapure & Mono element & Y & $12 \times 10^{3}$ & 5.9 & 30,40 & 0.42 & $0.4 \times 10^{2}$ & $190 \mathrm{mg} / \mathrm{g}$ \\
\hline $\begin{array}{l}{[99],} \\
2016\end{array}$ & GO & Ultrapure & Mono element & $\mathrm{Eu}$ & $\begin{array}{c}0.01 \times 10^{3} \\
\mathrm{NaCl}=0.01 \mathrm{M}\end{array}$ & $\begin{array}{c}5.0 \\
2.7-7.3\end{array}$ & r.t. & 48 & $1 \times 10^{2}$ & $\begin{array}{c}78.0 \mathrm{mg} / \mathrm{g} \\
97 \%\end{array}$ \\
\hline $\begin{array}{l}{[99],} \\
2016\end{array}$ & GO & Ultrapure & Mono element & $\mathrm{Eu}$ & $(0.01-100) \times 10^{3}$ & $\begin{array}{c}1-8 \\
2,4,6\end{array}$ & r.t. & 48 & $1 \times 10^{2}$ & \\
\hline $\begin{array}{l}{[98],} \\
2017\end{array}$ & GO & Ultrapure & Mono element & Sc & $300 \times 10^{3}$ & $\begin{array}{l}2 \\
4\end{array}$ & r.t. & 4 & $50 \times 10^{2}$ & $\begin{array}{c}\sim 95 \%, 36.5 \mathrm{mg} / \mathrm{g} \\
39.7 \mathrm{mg} / \mathrm{g}\end{array}$ \\
\hline $\begin{array}{l}{[98],} \\
2017\end{array}$ & GO & Ultrapure & Mono element & Sc & $(1-300) \times 10^{3}$ & $1-5.5$ & r.t. & $0.02-0.5$ & $50 \times 10^{2}$ & \\
\hline $\begin{array}{l}{[96],} \\
2017\end{array}$ & $\begin{array}{l}30 \% \mathrm{Mo}_{4} \mathrm{~W}_{8} @ \mathrm{ED} \\
30 \% \mathrm{Mo}_{2} \mathrm{~W}_{10} @ \mathrm{EI}\end{array}$ & Ultrapure & Mono element & $\mathrm{Ce}$ & $10 \times 10^{3}$ & $\begin{array}{c}6 \\
(2-6)\end{array}$ & 20 & $0.08-3$ & $17 \times 10^{2}$ & $\begin{array}{l}90.9 \mathrm{mg} / \mathrm{g}, \\
96.2 \mathrm{mg} / \mathrm{g}\end{array}$ \\
\hline
\end{tabular}


Table 5. Cont.

\begin{tabular}{|c|c|c|c|c|c|c|c|c|c|c|}
\hline $\begin{array}{l}\text { Ref., } \\
\text { Year }\end{array}$ & Sorbent & Type of Water & Type of System & REEs (III) & $\begin{array}{c}{[\text { REEs }]_{0}} \\
(\mu \mathrm{g} / \mathrm{L})\end{array}$ & $\mathrm{pH}$ & $\mathrm{T}\left({ }^{\circ} \mathrm{C}\right)$ & $\begin{array}{c}\text { Time of } \\
\text { Contact (h) }\end{array}$ & $\begin{array}{c}\mathrm{m}(\text { Sorbent)/ } \\
\mathrm{V}(\text { Solution) }(\mathrm{mg} / \mathrm{L})\end{array}$ & $\begin{array}{c}\mathrm{q}_{\mathrm{m}}(\mathrm{mg} / \mathrm{g}) \text { or } \\
\text { REEs Adsorption }(\%\end{array}$ \\
\hline $\begin{array}{l}{[95],} \\
2014\end{array}$ & MPANI-GO & Ultrapure & Multi elements & $\begin{array}{c}\text { Y, } \mathrm{La}, \mathrm{Ce}, \mathrm{Pr}, \mathrm{Nd}, \\
\mathrm{Sm}, \mathrm{Eu}, \mathrm{Gd}, \mathrm{Tb}, \mathrm{Dy}, \\
\mathrm{Ho}, \mathrm{Er}, \mathrm{Tm}, \mathrm{Yb}, \mathrm{Lu}\end{array}$ & $0.01 \times 10^{3}$ & 4 & r.t. & 0.33 & $4 \times 10^{2}$ & $\begin{aligned} \mathrm{Y} & =8.10, \mathrm{La}=15.5, \\
\mathrm{Ce} & =8.60, \mathrm{Pr}=11.1, \\
\mathrm{Nd} & =8.50, \mathrm{Sm}=7.70 \\
\mathrm{Eu} & =11.0, \mathrm{Gd}=16.3, \\
\mathrm{~Tb} & =11.8, \mathrm{Dy}=16.0, \\
\mathrm{Ho} & =8.10, \mathrm{Er}=15.2, \\
\mathrm{Tm} & =10.4, \mathrm{Yb}=10.3, \\
\mathrm{Lu} & =14.9 \mathrm{mg} / \mathrm{g}\end{aligned}$ \\
\hline $\begin{array}{l}{[96],} \\
2014\end{array}$ & MPANI-GO & Ultrapure & Multi elements & $\begin{array}{c}\text { Y, } \mathrm{La}, \mathrm{Ce}, \mathrm{Pr}, \mathrm{Nd}, \\
\mathrm{Sm}, \mathrm{Eu}, \mathrm{Gd}, \mathrm{Tb}, \mathrm{Dy} \text {, } \\
\mathrm{Ho}, \mathrm{Er}, \mathrm{Tm}, \mathrm{Yb}, \mathrm{Lu}\end{array}$ & $\begin{array}{c}(0.00025,0.0005,0.001 \\
0.002,0.01) \\
\times 10^{3}\end{array}$ & $2-9$ & r.t. & $\begin{array}{c}0.02-0.25 \\
0.33\end{array}$ & $(0.25-20) \times 10^{2}$ & \\
\hline $\begin{array}{l}{[90]} \\
2013\end{array}$ & PANI@GO & $\mathrm{HClO}_{4}(\mathrm{aq}) 0.01 \mathrm{~mol} / \mathrm{L}$ & Mono element & $\mathrm{Eu}$ & $15 \times 10^{3}$ & 3 & 25 & 48 & $2.5 \times 10^{2}$ & $251 \mathrm{mg} / \mathrm{g}$ \\
\hline $\begin{array}{l}{[97],} \\
2017\end{array}$ & $\begin{array}{l}\text { TGA/CdTeQDs } \\
\text { /Fe3O4/rGONS }\end{array}$ & Distilled & Mono element & $\mathrm{Ce}$ & $\begin{array}{c}0.05 \times 10^{3} \\
(1-100) \times 10^{3}\end{array}$ & 5.0 & 35 & 0.17 & $7 \times 10^{2}$ & $\begin{array}{c}95 \% \\
56.8 \mathrm{mg} / \mathrm{g}\end{array}$ \\
\hline $\begin{array}{l}{[102],} \\
2017\end{array}$ & $\begin{array}{l}\text { TGA/CdTeQDs } \\
\text { /Fe3O4/rGONS }\end{array}$ & Distilled & Mono element & $\mathrm{Ce}$ & $(1-100) \times 10^{3}$ & $2-8$ & 35 & $0.02-0.25$ & $(2-9) \times 10^{2}$ & \\
\hline $\begin{array}{l}{[102],} \\
2014\end{array}$ & GTiP-1 & Ultrapure & Mono element & $\mathrm{Eu}$ & $100 \times 10^{3}$ & $\begin{array}{c}1 \\
3.7 \\
5.5 \\
7.3\end{array}$ & 25 & 2 & $10 \times 10^{2}$ & $\begin{array}{c}\sim 3.0 \% \\
\sim 32 \% \\
35 \% \\
\sim 72 \%\end{array}$ \\
\hline $\begin{array}{l}{[103],} \\
2014\end{array}$ & GTiP-2 & Ultrapure & Mono element & $\mathrm{Eu}$ & $100 \times 10^{3}$ & \begin{tabular}{c|c|}
1 & \\
3.7 & \\
5.5 & \\
7.3 & \\
1 & \\
3.7 & \\
5.5 & \\
7.3 &
\end{tabular} & 25 & 2 & $10 \times 10^{2}$ & $\begin{array}{c}\sim 10 \% \\
\sim 45 \% \\
50 \% \\
\sim 80 \% \\
\sim 7.0 \% \\
\sim 20 \% \\
20 \% \\
\sim 28 \%\end{array}$ \\
\hline $\begin{array}{l}{[103],} \\
2014\end{array}$ & $\begin{array}{l}\text { GO, GTiP-1, } \\
\text { GTiP-2 }\end{array}$ & Ultrapure & Mono element & $\mathrm{Eu}$ & $\begin{array}{c}(5-200) \times 10^{3} \\
\mathrm{Na}^{+}=1,10,100,1000 \\
m M\end{array}$ & $\begin{array}{l}1.7,3.7 \\
5.5,7.3\end{array}$ & 25 & 2,4 & $10,000 \times 10^{2}$ & \\
\hline
\end{tabular}

(1) Adsorptions experiments were conducted under $\mathrm{N}_{2}$ conditions. r.t. means room temperature. The ultrapure water was provided by Milli-Q system. Note that the optimal experimental conditions are represented by shading and the other conditions tested and described in the papers are represented on a white background (without shading). 


\section{B. Carbon Nanotubes}

Carbon nanotubes (CNTs) are unique nano-structures with remarkable electronic and mechanical properties, either due to their close relationship with graphene, or because of their one-dimensional appearance. From the structural point of view, carbon nanotubes are divided into two main types of carbon nanotubes: Single-walled carbon nanotubes (SWCNTs), which can be considered as a single sheet of graphene rolled on itself to form a cylindrical tube, and multi-walled carbon nanotubes (MWCNTs), which consist of a set of concentric nanotubes stabilized by van der Waals forces [66]. The presence of concentric graphene sheets on MWCNTs enhance the interaction with the analytes [38].

The structure of the single-walled carbon nanotubes is determined by how close they are to themselves in the hexagonal network of graphene. These nanotubes can have three distinct forms (Figure 9), designated as an armchair, zigzag and chiral. The three arrangements present different electrical conduction properties, which result in the exceptional electronic properties of single wall carbon nanotubes. All carbon nanotubes of the armchair type are conductors, whereas the zigzag and chiral type can be conductors or semiconductors [66].

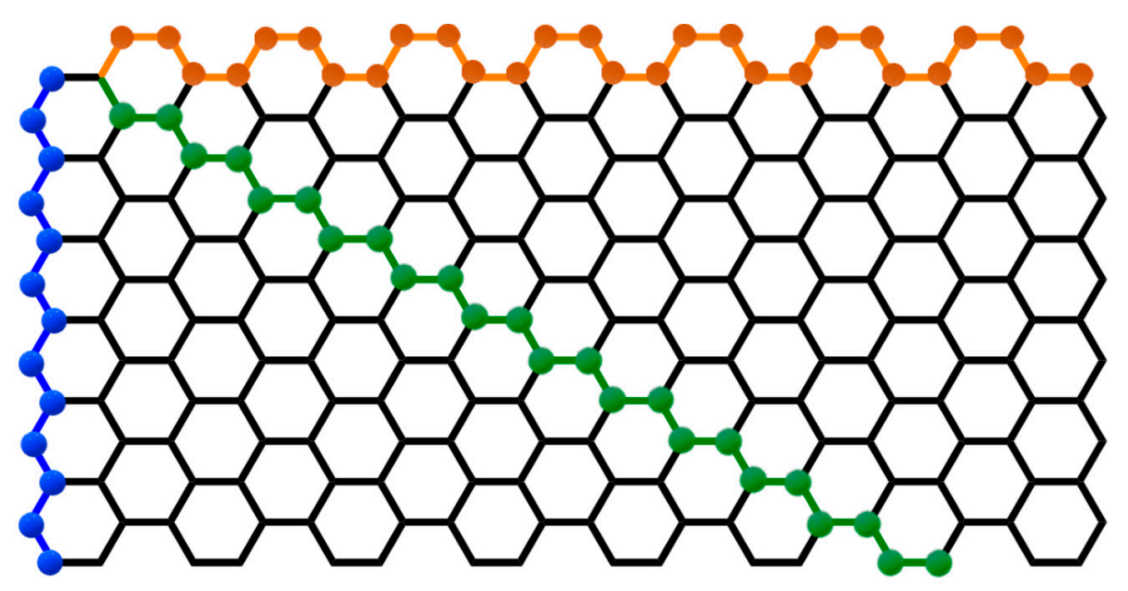

Figure 9. Classification of single-walled carbon nanotubes with distinct geometry and properties: Armchair (orange), zigzag (blue) and chiral (green).

Another important property is the carbon nanotubes insolubility in most liquids, such as water, polymer resins and in almost all solvents. So, to facilitate and standardize the dispersion of nanotubes in liquids, functional groups or polar molecules can be incorporated into the walls (Figure 10) without significantly altering their properties [66]. 


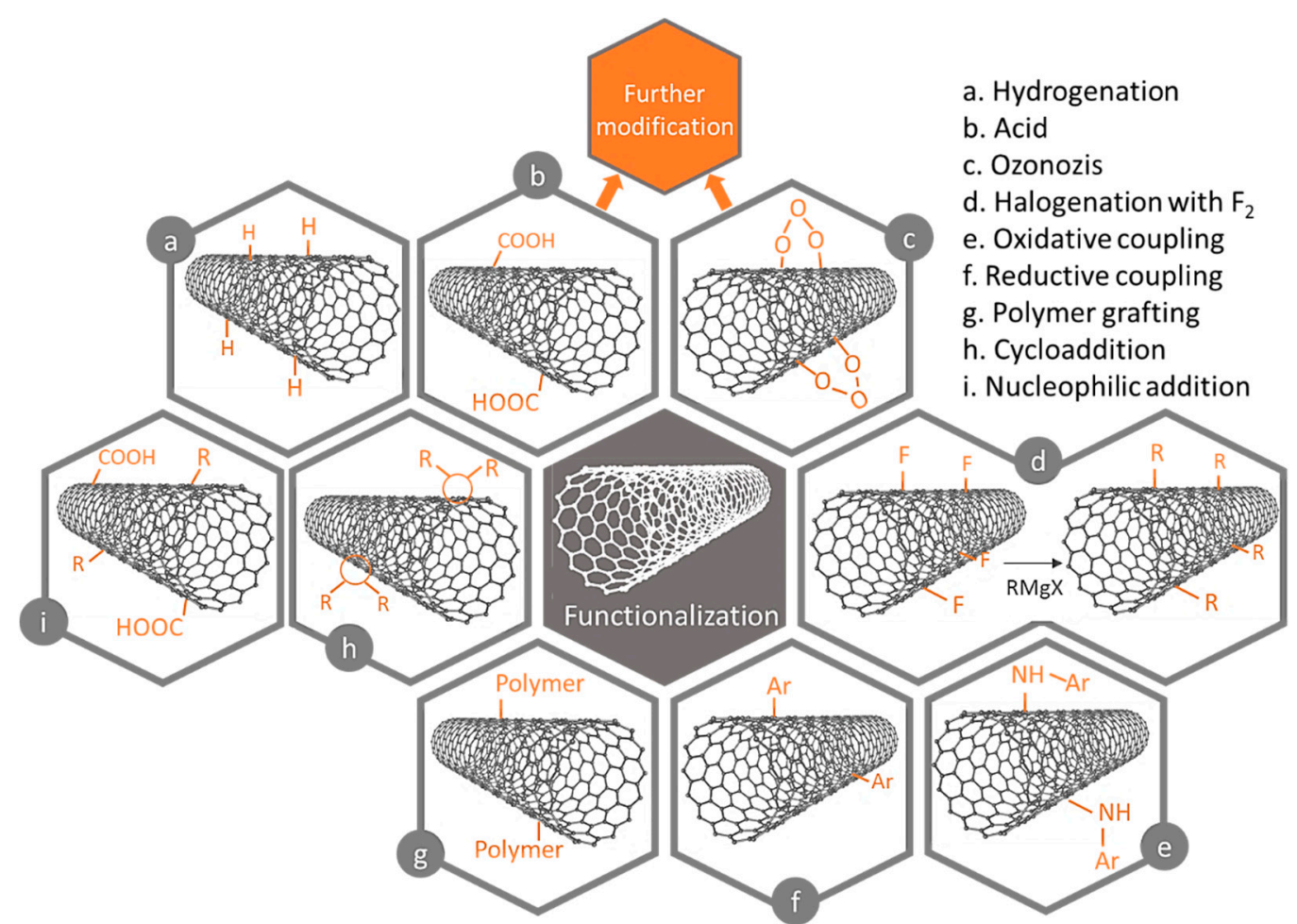

Figure 10. Overview of surface functionalization methods of over carbon nanotubes (CNTs).

\section{B1-Production of CNTs and Its Functionalizations}

Since its discovery, the methods of synthesis of carbon nanotubes have been continuously optimized, in order to obtain pure nanotubes in enough quantities. The main techniques of synthesis (Figure 11) can be divided into [66]: (i) High temperature methods, which include electric arc discharge and laser ablation; and (ii) methods at moderate temperatures, including chemical vapor deposition assisted by a catalyst [103]. This has been widely diffused and optimized, allowing even large-scale production [104]. Among these techniques, the most widely used for producing nanotubes is the electric arc discharge, is also used for the preparation of fullerene molecules. Either in single-walled tubes or multiple-walled tubes, process parameters, such as flow, gas pressure, and metal concentration need to vary to obtain the highest yield of carbon nanotubes [66].

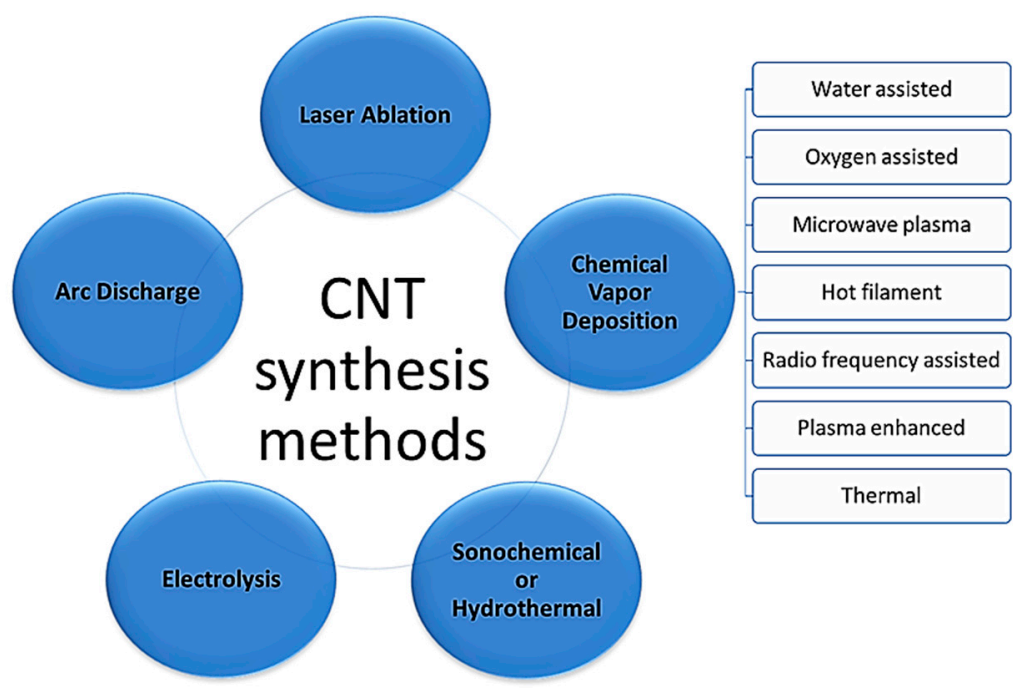

Figure 11. Different approaches to CNTs synthesis. 
Functionalization may be non-covalent (physical functionalization) or covalent (chemical functionalization), as represented in Figure 12. The non-covalent functionalization of nanotubes is based on the use of surfactants capable of making this material "soluble" in water; this process results from weak van der Waals interactions and $\pi-\pi$ type interactions. Covalent functionalization is based on the establishment of covalent bonds of functional ligands to the structures of the carbon nanotubes, which can occur at the ends or the tube walls. Functionalization in structural defects occurs through chemical transformations. Finally, the endohedral functionalization is the filling of the nanotubes with atoms or molecules of small dimensions. This type of modification, either by covalent or non-covalent functionalization, changes the surface properties, directly influencing the sorption capacity of the carbon nanotubes.

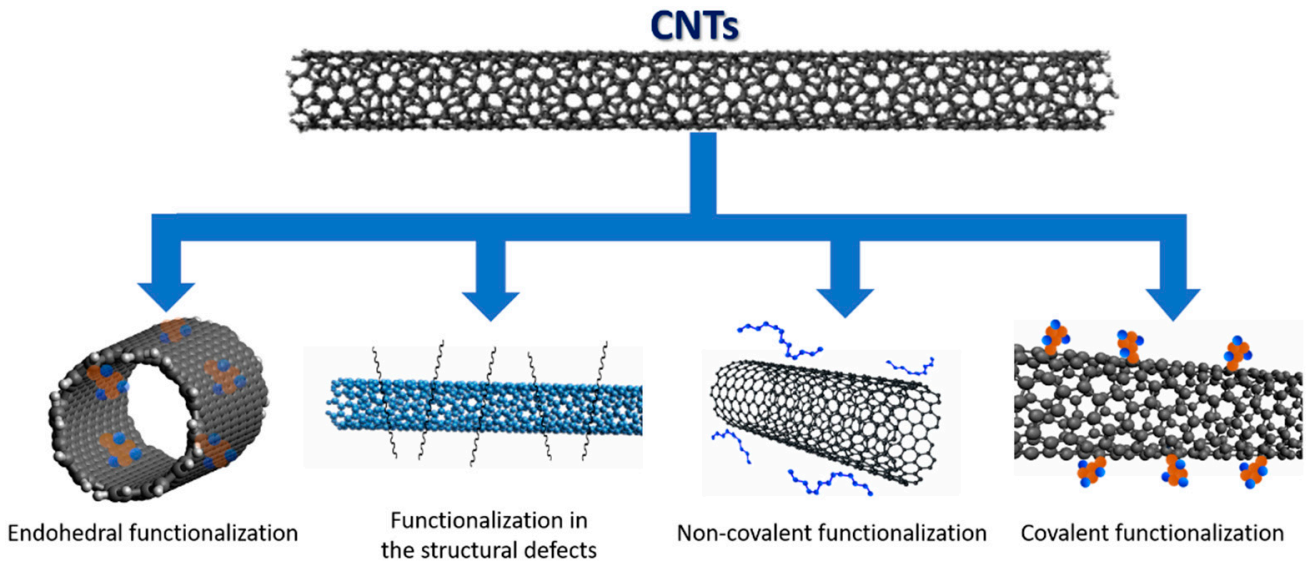

Figure 12. Types of functionalization methods of carbon nanotubes.

\section{B2-Recovery of Rare Earth Elements by Carbon Nanotubes}

Table 6 shows the studies of the recovery of REEs using carbon nanotubes composites. All the studies were performed in Milli-Q or distilled water, with the exception of only one study performed by Yadav et al. [105] that used $\mathrm{HCl}$ (aq, $0.5 \mathrm{M}$ ). Regarding the contact time between the nanocomposite and the rare earth solution, there was a wide range of times used, although no studies published exceeded 96 hours and the majority had 2-4 h duration [98,105-108]. Temperature was tested between 20 and $65^{\circ} \mathrm{C}$, although most of the reported studies were performed at $30{ }^{\circ} \mathrm{C}$ [105-107].

In most studies, the oxidized multi-walled carbon nanotubes (MWCNTs-oxidized) were chosen, since they are a more efficient and cheaper material when compared to the single-walled carbon nanotubes (SWCNTs-oxidized). In addition, some studies showed sorption experiments using CNTs with several functionalizations to improve even more their efficiency or to introduce other properties, such as magnetite $\left(\mathrm{Fe}_{3} \mathrm{O}_{4}\right)$ [109] with the purpose of affording magnetic properties to the material, or chitosan [108] to increase the maximum adsorption capacity of the material. It is possible to find, in the literature, ratios mass of sorbent per volume of solution from 600 to 100,000 mg/L for the REEs recovery, however, the most reported values were 600,1000 and $5000 \mathrm{mg} / \mathrm{L}$. The studies of Fan et al. [110], Chen et al. [109] and Chen et al. [111] were the ones that reported the lowest value of sorbent mass/volume (600 mg/L), which was used in the recovery of Eu(III) in mono-elemental solutions and at a $\mathrm{pH}$ between 5 and 6 . Finally, the material with the highest maximum adsorption capacity (qm) of REEs reported in the literature to the date was mIIP-CS/CNT composite with $121.51 \mathrm{mg} / \mathrm{g}$ achieved [108].

More studies used multi-elemental systems with CNTs composites than GO composites. The REEs studies in mono-elemental systems were scandium and europium, and in multi-elemental systems cerium, samarium, lanthanum, dysprosium, terbium, lutetium and gadolinium ions; yttrium was studied in both types of system. The two elements most studied were lanthanum and europium. Sorption studies in multi-elemental systems were limited to a maximum of three elements by Tong et al. [112] and Yadav et al. [105]. A wide variety of concentration intervals is published 
(Table 6), from $30 \mu \mathrm{g} / \mathrm{L}$ [111] to 1,000,000 $\mu \mathrm{g} / \mathrm{L}$ [105], being the most used concentrations between 10,000 and $40,000 \mu \mathrm{g} / \mathrm{L}$. The lower concentrations, namely 30 and $61 \mu \mathrm{g} / \mathrm{L}$ of Eu(III), in mono-elemental solutions, were reported by Chen et al. [111] and Chen et al. [109], respectively; moreover, K. Li et al. [108], Koochaki-Mohammadpour [107] and Behdani et al. [106] used 10,000 $\mu \mathrm{g} / \mathrm{L}$ for different REEs like $\mathrm{La}(\mathrm{III})$ and $\mathrm{Dy}$ (III) or Ce(III) and Sm(III), in multi-elemental solutions. Maximum adsorption values of REEs by CNTs composites are highly dependent on the chosen working $\mathrm{pH}$, affecting the surface charge and, consequently, the sorption of metal ions on CNTs. In general, increasing $\mathrm{pH}$ leads to the increase of metal ions sorption; this occurs because, at $\mathrm{pH}$ superior to $\mathrm{pH}$ PZC (point of zero charge), the positively-charged metal ions can be adsorbed on the negatively-charged oxidized CNTs [38]. In this way, the $\mathrm{pH}$ interval 5-7 were tested to find out the optimal $\mathrm{pH}$ and/or the working $\mathrm{pH}$. The most used working $\mathrm{pH}$ is $5[106,107,109,110,112]$; also, the lowest $\mathrm{pH}$ used was $1.5[98,112]$ whereas the highest working pH chosen was $8[106,110]$. Nevertheless, at least two studies in the literature have achieved adsorption rates of approximately 100\% using a $\mathrm{pH}$ of 5 [106] and 5.5 [109]. 
Table 6. Recovery of REEs using CNTs and the respectively experimental conditions used as reported in the literature.

\begin{tabular}{|c|c|c|c|c|c|c|c|c|c|c|}
\hline $\begin{array}{l}\text { Ref., } \\
\text { Year }\end{array}$ & Sorbent & Type of Water & Type of System & REEs (III) & $\begin{array}{c}{[\text { REEs }]_{0}} \\
(\mu \mathrm{g} / \mathrm{L})\end{array}$ & $\mathrm{pH}$ & $\mathrm{T}\left({ }^{\circ} \mathrm{C}\right)$ & $\begin{array}{c}\text { Time of } \\
\text { Contact (h) }\end{array}$ & $\begin{array}{c}\text { m (sorbent)/ V(solution) } \\
\text { (mg/L) }\end{array}$ & $\begin{array}{c}\mathrm{q}_{\mathrm{m}}(\mathrm{mg} / \mathrm{g}) \text { or } \\
\text { REEs Adsorption (\%) }\end{array}$ \\
\hline $\begin{array}{l}{[98],} \\
2017\end{array}$ & CNTs-COOH & Ultrapure & Mono element & $\mathrm{Sc}$ & $300 \times 10^{3}$ & $\begin{array}{l}2 \\
4\end{array}$ & r.t. & 4 & $50 \times 10^{2}$ & $\begin{array}{l}37.9 \mathrm{mg} / \mathrm{g} \\
42.5 \mathrm{mg} / \mathrm{g}\end{array}$ \\
\hline $\begin{array}{l}{[98],} \\
2017\end{array}$ & CNTs-COOH & Ultrapure & Mono element & $\mathrm{Sc}$ & $(1-300) \times 10^{3}$ & $1-5.5$ & r.t. & $0.02-0.5$ & $50 \times 10^{2}$ & - \\
\hline $\begin{array}{l}{[106],} \\
2013\end{array}$ & MWCNTs-oxidized & Distilled & Multi elements & $\mathrm{Ce}$ & $\begin{array}{l}20 \times 10^{3} \\
20 \times 10^{3} \\
10 \times 10^{3}\end{array}$ & 5 & 30 & 2 & $\begin{array}{l}12 \times 10^{2} \\
10 \times 10^{2} \\
10 \times 10^{2}\end{array}$ & $\begin{array}{l}\sim 87 \% \\
\sim 82 \% \\
\sim 97 \%\end{array}$ \\
\hline $\begin{array}{l}{[107],} \\
2013\end{array}$ & MWCNTs-oxidized & Distilled & Multi elements & $\mathrm{Sm}$ & $\begin{array}{l}20 \times 10^{3} \\
20 \times 10^{3} \\
10 \times 10^{3}\end{array}$ & 5 & 30 & 2 & $\begin{array}{l}12 \times 10^{2} \\
10 \times 10^{2} \\
10 \times 10^{2}\end{array}$ & $\begin{array}{c}\sim 98 \% \\
\sim 95 \% \\
\sim 100 \%\end{array}$ \\
\hline $\begin{array}{l}{[107],} \\
2013\end{array}$ & MWCNTs-oxidized & Distilled & Multi elements & $\begin{array}{l}\mathrm{Ce}, \\
\mathrm{Sm}\end{array}$ & $\begin{array}{c}(10,20,50,75,100,150 \\
200) \times 10^{3}\end{array}$ & $2-8$ & $\begin{array}{l}30,40,50, \\
\quad 60\end{array}$ & $\begin{array}{c}0.08,0.17 \\
0.25,0.33 \\
0.5,0.67 \\
0.83,1,1.25 \\
1.5,2\end{array}$ & $(2,4,6,8,10,12) \times 10^{2}$ & - \\
\hline $\begin{array}{l}{[107],} \\
2014\end{array}$ & MWCNTs-oxidized & Distilled & Multi elements & $\mathrm{La}$ & $\begin{array}{l}20 \times 10^{3} \\
20 \times 10^{3} \\
10 \times 10^{3}\end{array}$ & 5 & 30 & 2 & $\begin{array}{l}12 \times 10^{2} \\
10 \times 10^{2} \\
10 \times 10^{2}\end{array}$ & $\begin{array}{l}80 \% \\
80 \% \\
93 \%\end{array}$ \\
\hline $\begin{array}{l}{[108],} \\
2014\end{array}$ & MWCNTs-oxidized & Distilled & Multi elements & Dy & $\begin{array}{l}20 \times 10^{3} \\
20 \times 10^{3} \\
10 \times 10^{3}\end{array}$ & 5 & 30 & 2 & $\begin{array}{l}12 \times 10^{2} \\
10 \times 10^{2} \\
10 \times 10^{2}\end{array}$ & $\begin{array}{l}98 \% \\
97 \% \\
98 \%\end{array}$ \\
\hline $\begin{array}{l}{[108],} \\
2014\end{array}$ & MWCNTs-oxidized & Distilled & Multi elements & La, Dy & $(10-200) \times 10^{3}$ & $2-6$ & $\begin{array}{l}30,40,50 \\
\quad 60\end{array}$ & $\begin{array}{c}0.08,0.17 \\
0.25,0.33 \\
0.5,0.67 \\
0.83,1,1.25 \\
1.5,2\end{array}$ & $\begin{array}{l}(2-12) \\
\times 10^{2}\end{array}$ & \\
\hline $\begin{array}{l}{[112],} \\
2011\end{array}$ & TA-MWCNTs & Distilled & Multi elements & $\begin{array}{l}\mathrm{La} \\
\mathrm{Tb} \\
\mathrm{Lu}\end{array}$ & $40 \times 10^{3}$ & 5 & 20 & - $201-$ & $50 \times 10^{2}$ & $\begin{array}{l}5.35 \mathrm{mg} / \mathrm{g}, \\
8.55 \mathrm{mg} / \mathrm{g}, \\
3.97 \mathrm{mg} / \mathrm{g}\end{array}$ \\
\hline $\begin{array}{l}{[113],} \\
2011\end{array}$ & TA-MWCNTs & Distilled & Mono element & $\mathrm{La}$ & $40 \times 10^{3}$ & 5 & 20 & 1 & $\begin{array}{l}50 \times 10^{2} \\
\text { (with } 0.12 \times 10^{2} \text { being TA) }\end{array}$ & $75 \%$ \\
\hline $\begin{array}{l}{[113],} \\
2011\end{array}$ & TA-MWCNTs & Distilled & Multi elements & $(\mathrm{La}, \mathrm{Tb}, \mathrm{Lu})$ & $40 \times 10^{3}$ & $1.5-4$ & 20 & 1 & $50 \times 10^{2}$ & $0.4-6.0 \mathrm{mg} / \mathrm{g}$ \\
\hline $\begin{array}{l}{[113],} \\
2011\end{array}$ & TA-MWCNTs & Distilled & Multi elements & $(\mathrm{La}, \mathrm{Tb}, \mathrm{Lu})$ & $(5-50) \times 10^{3}$ & $1.5-7$ & 20 & $0.08-2$ & $(20-200) \times 10^{2}$ & - \\
\hline $\begin{array}{l}{[110],} \\
2009\end{array}$ & MWCNTs-oxidized & Milli-Q & Mono element & $\mathrm{Eu}$ & $0.99 \times 10^{3}$ & $\begin{array}{c}5 \\
(2-8)\end{array}$ & 25 & 96 & $6 \times 10^{2}$ & $90.0 \%$ \\
\hline $\begin{array}{l}{[109],} \\
2009\end{array}$ & $\begin{array}{l}\mathrm{MWCNTs} / \mathrm{Fe}_{3} \mathrm{O}_{4} \\
\text { composite }\end{array}$ & Milli-Q & Mono element & $\mathrm{Eu}^{\mathrm{a}}$ & $\begin{array}{c}0.061 \times 10^{3} \\
\mathrm{NaClO}_{4}=0.1 \mathrm{~mol} / \mathrm{L}\end{array}$ & 5.5 & 25 & 48 & $6 \times 10^{2}$ & $\sim 100 \%$ \\
\hline $\begin{array}{l}{[110],} \\
2009\end{array}$ & $\begin{array}{l}\mathrm{MWCNTS} / \mathrm{Fe}_{3} \mathrm{O}_{4} \\
\text { composite }\end{array}$ & Milli-Q & Mono element & $\mathrm{Eu}^{\mathrm{a}}$ & $\begin{array}{c}0.61 \times 10^{3} \\
6.1 \times 10^{3}\end{array}$ & $2.5-7$ & 25 & 48 & $6 \times 10^{2}$ & - \\
\hline
\end{tabular}


Table 6. Cont.

\begin{tabular}{|c|c|c|c|c|c|c|c|c|c|c|}
\hline $\begin{array}{l}\text { Ref., } \\
\text { Year }\end{array}$ & Sorbent & Type of Water & Type of System & REEs (III) & $\begin{array}{c}{[\text { REEs }]_{0}} \\
(\mu \mathrm{g} / \mathrm{L})\end{array}$ & $\mathrm{pH}$ & $\mathrm{T}\left({ }^{\circ} \mathrm{C}\right)$ & $\begin{array}{c}\text { Time of } \\
\text { Contact (h) }\end{array}$ & $\begin{array}{c}\mathrm{m} \text { (sorbent)/ V(solution) } \\
(\mathrm{mg} / \mathrm{L})\end{array}$ & $\begin{array}{c}\mathrm{q}_{\mathrm{m}}(\mathrm{mg} / \mathrm{g}) \text { or } \\
\text { REEs Adsorption (\%) }\end{array}$ \\
\hline $\begin{array}{l}{[105],} \\
2015\end{array}$ & & & Mono element & $\mathrm{Y}$ & $1000 \times 10^{3}$ & - & 30 & 8 & $1000 \times 10^{2}$ & $95 \%$ \\
\hline $\begin{array}{l}{[106],} \\
2015\end{array}$ & $\begin{array}{l}\text { PES/PVA/MWCNT/ } \\
\text { D2EHPA beads }\end{array}$ & $\begin{array}{c}\mathrm{HCl} \\
(\mathrm{aq}, 0.5 \mathrm{~mol} / \mathrm{L})\end{array}$ & & Y & $(80-3300) \times 10^{3}$ & - & $30-65$ & $0-8$ & $1000 \times 10^{2}$ & $44.1 \mathrm{mg} / \mathrm{g}$ \\
\hline $\begin{array}{l}{[106],} \\
2015\end{array}$ & & & Multi elements & $\begin{array}{l}\mathrm{Y} \\
\mathrm{Sm} \\
\mathrm{La}\end{array}$ & $100 \times 10^{3}$ & - & 30 & 4 & $1000 \times 10^{2}$ & $\begin{array}{l}94 \% \\
82 \% \\
30 \%\end{array}$ \\
\hline $\begin{array}{l}{[106],} \\
2015\end{array}$ & $\begin{array}{l}\text { PES/PVA/MWCNT/ } \\
\text { D2EHPA beads }\end{array}$ & $\begin{array}{c}\mathrm{HCl} \\
(\mathrm{aq}, 0.5 \mathrm{~mol} / \mathrm{L})\end{array}$ & Multi elements & Y, Sm, La & $(150-1000) \times 10^{3}$ & - & 30 & $0-8$ & $1000 \times 10^{2}$ & - \\
\hline $\begin{array}{l}{[111],} \\
2008\end{array}$ & MWCNTs-oxidized & Distilled & Mono element & $\mathrm{Eu}$ & $\begin{array}{c}0.03 \times 10^{3} \\
\mathrm{NaClO}_{4}=0.001,0.01 \\
0.1 \mathrm{~mol} / \mathrm{L} \\
\end{array}$ & $\begin{array}{c}6 \\
(2-7)\end{array}$ & 25 & 48 & $6 \times 10^{2}$ & $\begin{array}{l}98 \% \\
\text { for all the ionic strengths }\end{array}$ \\
\hline $\begin{array}{l}{[108],} \\
2015\end{array}$ & $\begin{array}{l}\text { mIIP-CS/CNT } \\
\text { composite }\end{array}$ & Distilled & Multi elements & $\mathrm{Gd}^{\mathrm{b}}$ & $10 \times 10^{3}$ & 7 & $\begin{array}{l}20 \\
33 \\
43\end{array}$ & 4 & $20 \times 10^{2 c}$ & $\begin{array}{l}79.5 \mathrm{mg} / \mathrm{g} \\
109 \mathrm{mg} / \mathrm{g} \\
122 \mathrm{mg} / \mathrm{g}\end{array}$ \\
\hline $\begin{array}{l}{[109],} \\
2015\end{array}$ & $\begin{array}{l}\text { mNIP-CS/CNT } \\
\text { composite }\end{array}$ & Distilled & Multi elements & $\mathrm{Gd}^{\mathrm{b}}$ & $10 \times 10^{3}$ & 7 & 33 & 4 & $20 \times 10^{2 \mathrm{c}}$ & $96.2 \mathrm{mg} / \mathrm{g}$ \\
\hline $\begin{array}{l}{[109],} \\
2015\end{array}$ & $\begin{array}{c}\text { mIIP-CS/CNT } \\
\text { and mNIP-CS/CNT } \\
\text { composites }\end{array}$ & Distilled & Multi elements & $\mathrm{Gd}^{\mathrm{b}}$ & $(2,10,50,100,200) \times 10^{3}$ & $2-7$ & $20,33,43$ & $0.05-8$ & $20 \times 10^{2 \mathrm{c}}$ & - \\
\hline
\end{tabular}

a Adsorptions experiments under $\mathrm{N}_{2}$ conditions. ${ }^{\mathrm{b}} \mathrm{Gd}^{3+}$ adsorption experiments with two competitive ions (La ${ }^{3+}$ and/or Ce ${ }^{3+}$ ). ${ }^{\mathrm{c}} 10 \mathrm{mg}$ of IIP-CS/CNT (or NIP-CS/CNT) and $30 \mathrm{mg}$ of $\mathrm{SiO}_{2} @ \mathrm{Fe}_{3} \mathrm{O}_{4}$ were added into a vial, which contained $20 \mathrm{~mL}$ of REEs. Optimal experimental conditions are represented by shading and the other conditions tested and described in the papers are represented on a white background (without shading). 


\section{Other Carbon Materials}

Activated carbon is a material composed mostly of carbon, very porous, and it is considered one of the adsorbents with a greater capacity of adsorption. Its main characteristic is its high internal surface area developed during activation, formed by thousands of pores classified in micro, meso and macropores. Activated carbons are typically used to purify or separate gas and liquid mixtures [113,114] because of their high adsorption capacity; however, commercially activated carbons generally have high costs which may limit their use. The most common forms in which they are marketed are powdered activated carbon (PAC) and granular activated carbon (GAC). GAC is most frequently used in the removal of water pollutants, since it allows a continuous process in columns of fixed and immobile beds through which the fluid passes and is purified [114].

A fullerene is a molecule of carbon in the form of a hollow sphere, ellipsoid, tube, and many other shapes. Basically, fullerenes are closed hollow cages made of $\mathrm{sp}^{2}$-hybridized carbon atoms arranged into 12 pentagons and a calculable number of hexagons that depends on the total number of carbon atoms. $\mathrm{C} 60$ is the most abundant and the most widely studied, to date. C60 and other larger fullerenes (C70, C76, C82, and C84) can be viewed as a carbon nanoallotrope with hybridization between $\mathrm{sp}^{2}$ and $\mathrm{sp}^{3}$. The presence of pentagons is essential, introducing curvature and, hence, allowing closing of the cage [113].

Carbon dots or C-dots are quasi-spherical carbon nanoparticles with diameters of 2-10 nm that have high oxygen contents and consist of combinations of graphitic and turbostratic carbon in various volumetric ratios. The most characteristic and significant property of C-dots is relatively strong photo-luminescence, which depends on their size, the excitation wavelength, and the surface functionalization [113].

Carbon nanofibers (CNFs) are described as a non-continuous 1D carbon nanoallotrope of cylindrical or conical shape, consisting of stacked and curved graphene sheets arranged in various ways. They are frequently described as $\mathrm{sp}^{2}$-based linear filaments with a diameter ranging from 50 to $200 \mathrm{~nm}$ and a high aspect ratio exceeding 100 . CNFs have special surface morphology, steady structure characteristics, surface properties which can be modified through chemical treatments to achieve a specific goal and they are also easily available on a large scale. For these reasons, CNFs may have great analytical potential as an effective SPE adsorbent [113].

Carbon black (CB) is a material produced by the incomplete combustion of heavy petroleum products (such as FCC tar and ethylene cracking tar) with the addition of a small amount of vegetable oil. Carbon black is a form of paracrystalline carbon that has a high surface-area-to-volume ratio, although lower than activated carbon. His mainly used as a reinforcing filler in tires and other rubber products; as color pigments in plastics, paints, and inks, and as SPE adsorbent for chemical product recovery [115].

\section{C1-Recovery of REEs Using Other Carbon Materials}

Table 7 represented the studies of the REEs recovery using the other types of carbon materials which do not belong to the graphene or carbon nanotubes families (activated carbon, fullerenes, carbon dots, mesoporous carbon, carbon nanofibers and carbon black). Again, this review is only focused on batch experimental studies whereby there are a few studies in the literature that are not been explored in this review because they are column experiments [38,116-118]. However, it was possible to verify that carbon nanotubes and carbon nanofibers are the most used materials for column experimental studies. 
Table 7. Recovery of REEs using other carbon materials (Activated Carbon, Fullerene, C-Dots, Carbon Black, Mesoporous Carbon, Carbon nanofibers) and the respectively experimental conditions used as reported in the literature.

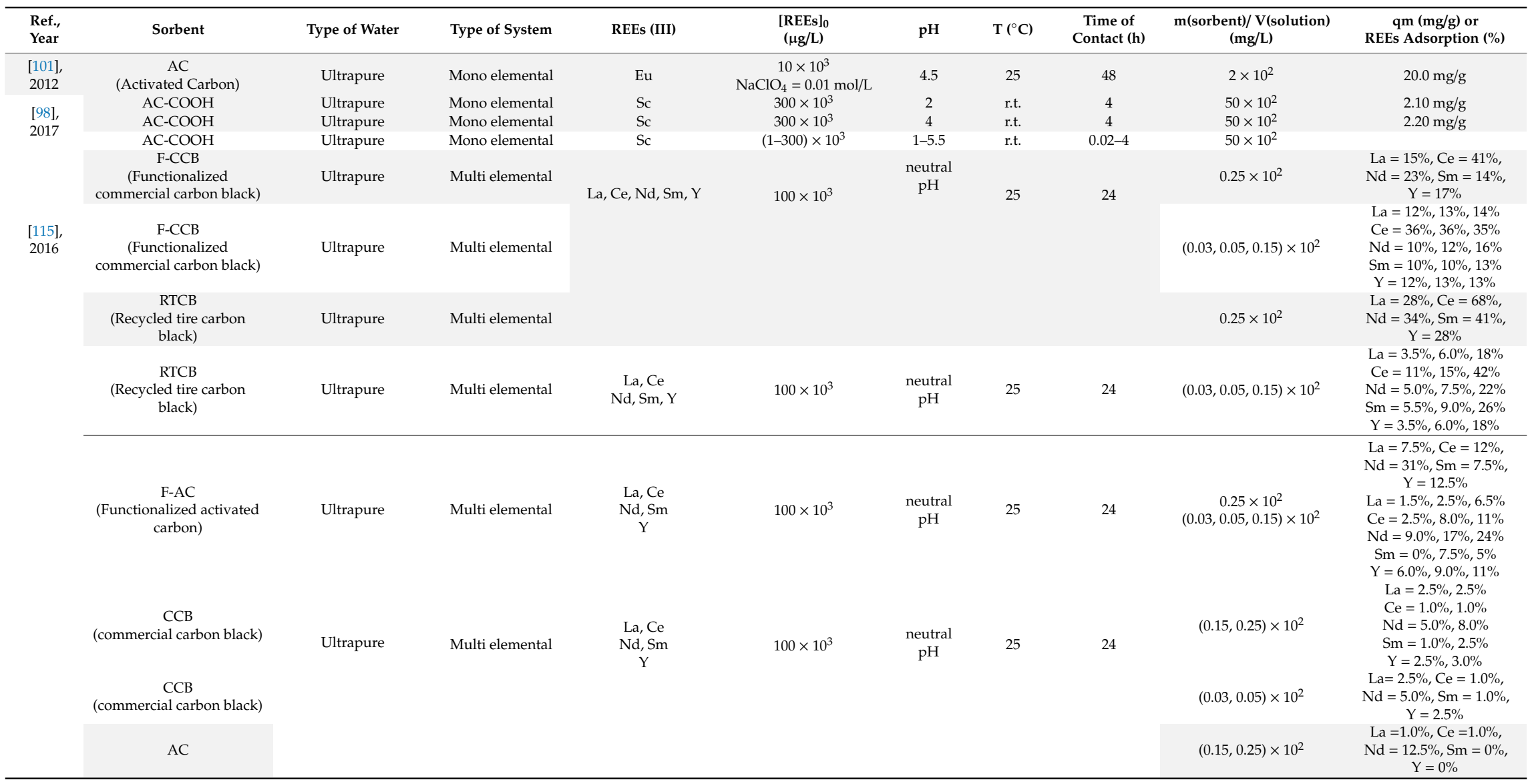


Table 7. Cont.

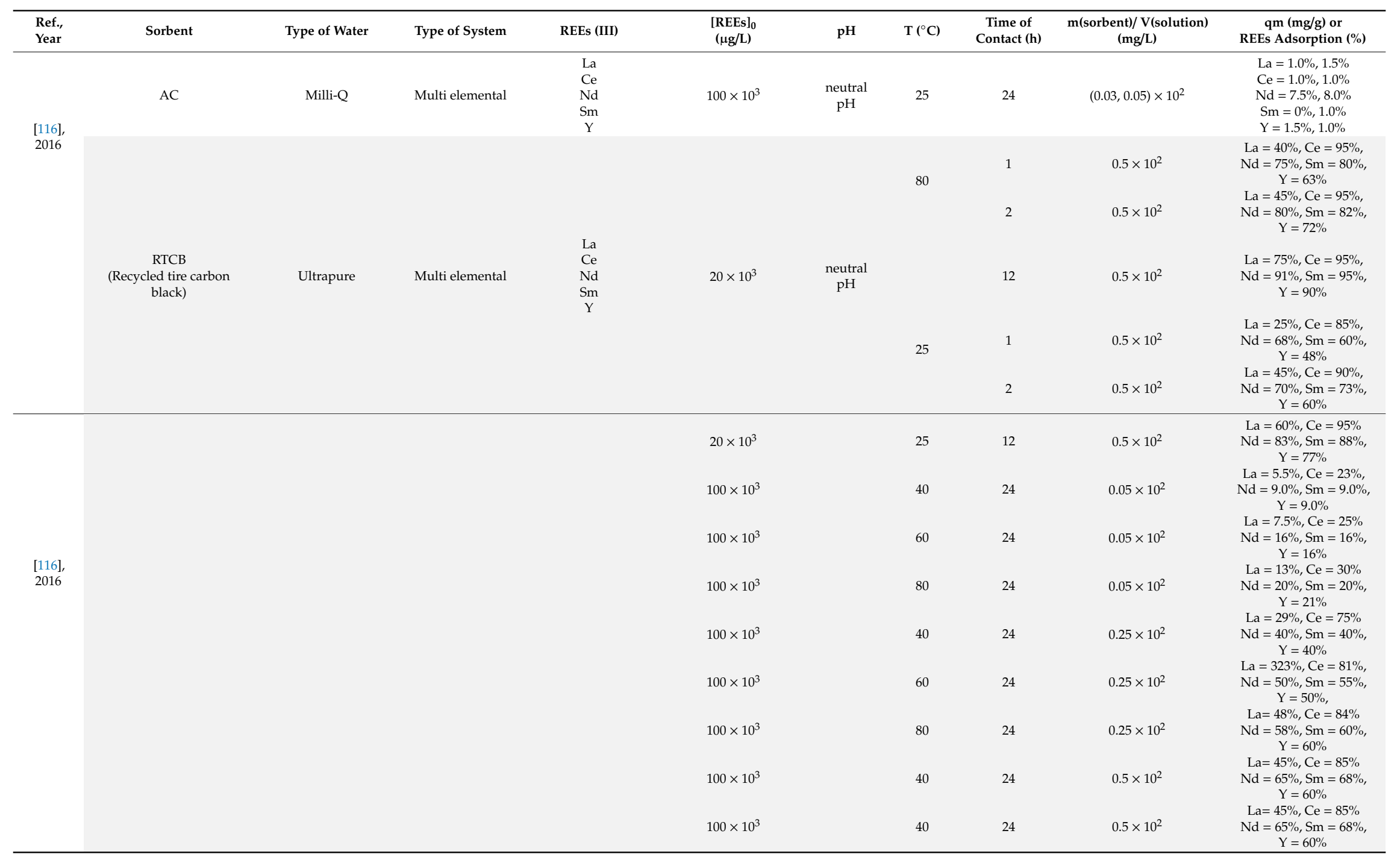


Table 7. Cont

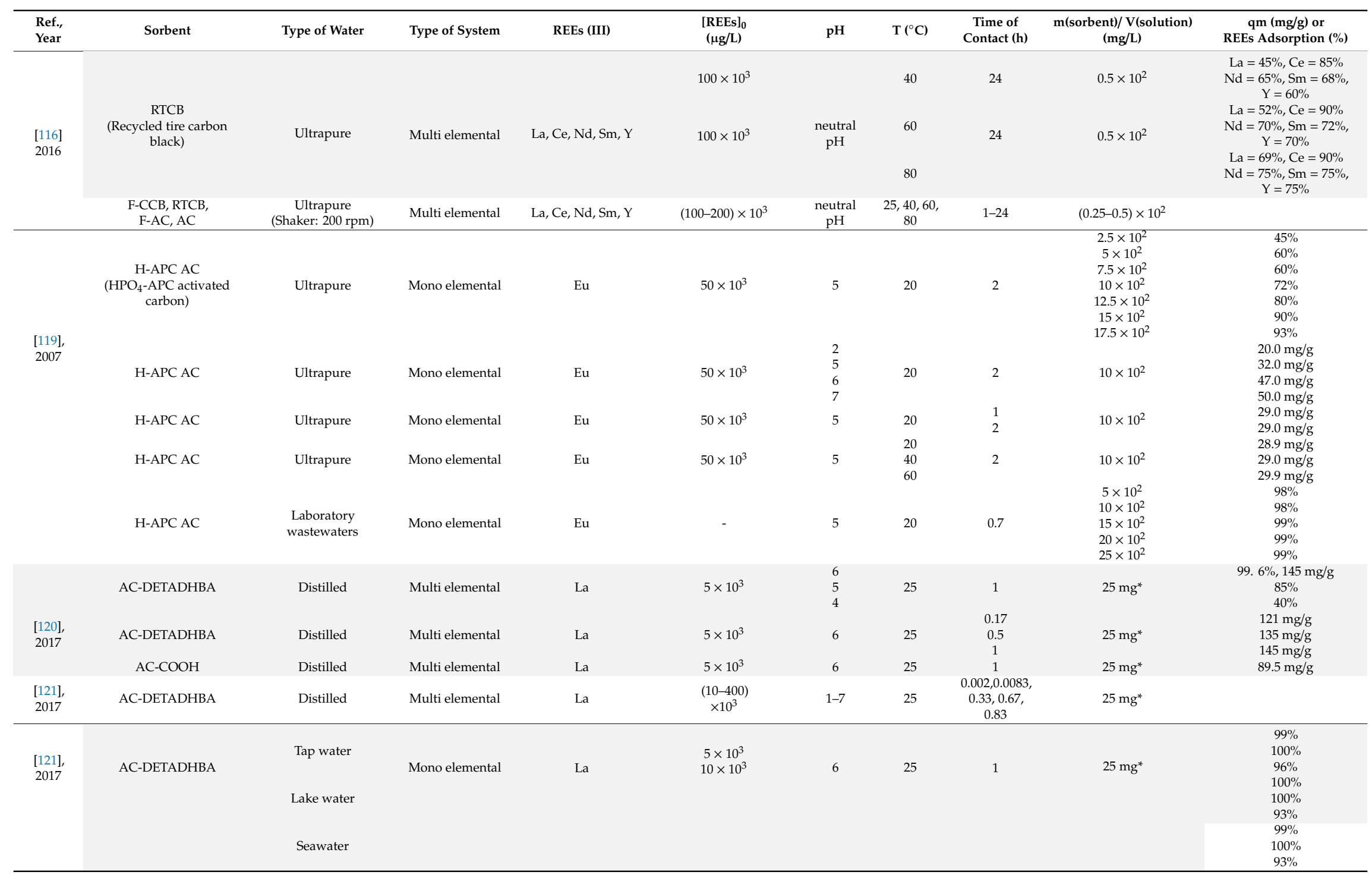


Table 7. Cont

\begin{tabular}{|c|c|c|c|c|c|c|c|c|c|c|}
\hline $\begin{array}{l}\text { Ref., } \\
\text { Year }\end{array}$ & Sorbent & Type of Water & Type of System & REEs (III) & $\begin{array}{c}{[\text { REEs }]_{0}} \\
(\mu \mathrm{g} / \mathrm{L})\end{array}$ & $\mathrm{pH}$ & $\mathrm{T}\left({ }^{\circ} \mathrm{C}\right)$ & $\begin{array}{c}\text { Time of } \\
\text { Contact (h) }\end{array}$ & $\begin{array}{c}\mathrm{m} \text { (sorbent)/ V(solution) } \\
(\mathrm{mg} / \mathrm{L})\end{array}$ & $\begin{array}{c}\mathrm{qm}(\mathrm{mg} / \mathrm{g}) \text { or } \\
\text { REEs Adsorption (\%) }\end{array}$ \\
\hline \multirow[t]{2}{*}{$\begin{array}{l}{[121],} \\
2017\end{array}$} & \multirow[t]{2}{*}{$\begin{array}{l}\text { Phosphorous } \\
\text { functionalized } \\
\text { nanoporous carbon }\end{array}$} & \multirow[t]{2}{*}{ Ultrapure } & \multirow[t]{2}{*}{ Multi elemental } & \multirow[t]{2}{*}{$\begin{array}{l}\mathrm{Nd} \\
\mathrm{Dy}\end{array}$} & \multirow[t]{2}{*}{$0.5 \times 10^{3}$} & \multirow[t]{2}{*}{$\begin{array}{l}6.1 \\
6.6\end{array}$} & \multirow[t]{2}{*}{25} & 4 & \multirow[t]{2}{*}{$10 \times 10^{2}$} & $\begin{array}{l}\mathrm{Nd}=336 \mathrm{mg} / \mathrm{g} \\
\mathrm{Dy}=344 \mathrm{mg} / \mathrm{g}\end{array}$ \\
\hline & & & & & & & & $\begin{array}{c}3 \\
0.033\end{array}$ & & $\begin{array}{l}\mathrm{Nd}=68,0 \% \\
\mathrm{Dy}=67.0 \%\end{array}$ \\
\hline \multirow{6}{*}{$\begin{array}{l}{[122],} \\
2017\end{array}$} & CMK-8 & Milli-Q & Multi elemental & $\mathrm{Sm}$ & $0.02 \times 10^{3}$ & 2.6 & r.t. & $\begin{array}{l}0.5 \\
2.5\end{array}$ & $10 \times 10^{2}$ & $\begin{array}{c}1 \mathrm{mg} / \mathrm{g} \\
1.5 \mathrm{mg} / \mathrm{g}\end{array}$ \\
\hline & $\begin{array}{c}\text { CMK-8-O } \\
\text { (CMK-8-Oxidezed) }\end{array}$ & Milli-Q & Multi elemental & Sm & $0.07 \times 10^{3}$ & 2.6 & r.t. & $\begin{array}{c}0.5 \\
1 \\
2.5\end{array}$ & $10 \times 10^{2}$ & $\begin{array}{c}14 \mathrm{mg} / \mathrm{g} \\
13.8 \mathrm{mg} / \mathrm{g} \\
13 \mathrm{mg} / \mathrm{g}\end{array}$ \\
\hline & $\begin{array}{c}\text { CMK-8-DGO } \\
\text { (DGO: Diglycolyl-type } \\
\text { organic) }\end{array}$ & Milli-Q & Multi elemental & La & $0.0003 \times 10^{3}$ & $\begin{array}{l}2.6 \\
3.8 \\
5.7\end{array}$ & r.t. & 4 & $10 \times 10^{2}$ & $\begin{array}{l}23 \mathrm{mg} / \mathrm{g} \\
27 \mathrm{mg} / \mathrm{g} \\
22 \mathrm{mg} / \mathrm{g}\end{array}$ \\
\hline & CMK-8 & Milli-Q & Multi elemental & $\mathrm{Sm}$ & $(0.0025-0.025) \times 10^{3}$ & 2.6 & r.t. & 4 & $10 \times 10^{2}$ & $8 \mathrm{mg} / \mathrm{g}$ \\
\hline & $\begin{array}{c}\text { CMK-8-O } \\
\text { (CMK-8-Oxidezed) }\end{array}$ & Milli-Q & Multi elemental & Sm & $(0.05-0.2) \times 10^{3}$ & 2.6 & r.t. & 4 & $10 \times 10^{2}$ & $23 \mathrm{mg} / \mathrm{g}$ \\
\hline & $\begin{array}{c}\text { CMK-8-DGO } \\
\begin{array}{c}\text { (DGO: Diglycolyl-type } \\
\text { organic) }\end{array}\end{array}$ & Milli-Q & Multi elemental & $\mathrm{La}$ & $(0.01-0.1) \times 10^{3}$ & 2.6 & r.t. & 4 & $10 \times 10^{2}$ & $10 \mathrm{mg} / \mathrm{g}$ \\
\hline
\end{tabular}

* There is not any mention of the volume of REEs solution used. - The optimal experimental conditions are represented by shading and the other conditions tested and described in the papers are represented on a white background (without shading). 
All the studies were performed in Milli-Q, with the exception of two studies by Gad and Awwad [119] that used laboratory wastewaters in addition to Milli-Q water and Marwani et al. [120] that used distilled water, tap water, lake water and seawater. Regarding the contact time between the nanocomposite and the rare earth solution, there was a wide range of times, nevertheless, there are no studies published over $48 \mathrm{~h} \mathrm{[101]} \mathrm{and} \mathrm{the} \mathrm{majority} \mathrm{of} \mathrm{the} \mathrm{studies} \mathrm{performed} \mathrm{had} \mathrm{a} \mathrm{duration} \mathrm{time} \mathrm{of} 1$ and $24 \mathrm{~h}[115,119,120]$. A wide range of temperature $\left(20-80^{\circ} \mathrm{C}\right)$ was, although most of the reported studies were performed at room temperature, $25^{\circ} \mathrm{C}$.

Activated carbon is the most used material, with various types of functionalization. Ratios mass of sorbent per volume of solution were between $3 \mathrm{mg} / \mathrm{L}$ and $5000 \mathrm{mg} / \mathrm{L}$ and the most reported ratio was $1000 \mathrm{mg} / \mathrm{L}$. The study of Smith et al. [115] reported the lowest values of sorbent mass/volume (3 and $25 \mathrm{mg} / \mathrm{L}$ ), which was used in the recovery of $\mathrm{La}(\mathrm{III}), \mathrm{Ce}(\mathrm{III}), \mathrm{Nd}(\mathrm{III}), \mathrm{Sm}$ (III) and Y(III) in multi-elemental solutions and at neutral $\mathrm{pH}$. Finally, the material with the highest maximum adsorption capacity (qm) of REEs reported in the literature was oxygen and phosphorus functionalized nanoporous carbon with $335.5 \mathrm{mg} / \mathrm{g}$ and $344.6 \mathrm{mg} / \mathrm{g}$ achieved of $\mathrm{Nd}$ and Dy, respectively, at pH 6.1 and 6.6 in multi-elemental solution [121]. However, the best removal rate achieved was $99.6 \%$ of La by BETADHBA functionalized activated carbon at pH 6 [121].

It was found more studies using multi-elemental systems with these materials than multi-elemental systems with GO composites. $\mathrm{La}(\mathrm{III}), \mathrm{Nd}(\mathrm{III})$ and $\mathrm{Eu}(\mathrm{III})$ were the elements most studied. Most of the studies have used concentrations from $0.3 \mu \mathrm{g} / \mathrm{L}$ [122] to 300,000 $\mu \mathrm{g} / \mathrm{L}$ [98], although most of the values used were from 50,000 to 100,000 $\mu \mathrm{g} / \mathrm{L}$. The studies of Perreault et al. [122] used the lower concentrations values, namely 70 and $0.3 \mu \mathrm{g} / \mathrm{L}$ of $\mathrm{Sm}(\mathrm{III})$ and $\mathrm{La}(\mathrm{III})$, respectively. Sorption is highly dependent on the chosen working $\mathrm{pH}$. The most used working $\mathrm{pH}$ were 5 and 6; the lowest $\mathrm{pH}$ used was $2[98,119,122]$ and the highest working $\mathrm{pH}$ was 7 [115,121]. A clear example that evidences this $\mathrm{pH}$ dependence on REEs adsorption is the study of Gad and Awwad [119] which got an increase of adsorption capacity from $20 \mathrm{mg} / \mathrm{g}$ at $\mathrm{pH} 2$ for $32 \mathrm{mg} / \mathrm{g}$ at $\mathrm{pH} 5,47 \mathrm{mg} / \mathrm{g}$ at $\mathrm{pH} 6$ and $50 \mathrm{mg} / \mathrm{g}$ of Eu at $\mathrm{pH} 7$. Furthermore, the study of Marwani et al. [120] demonstrates an increase of sorption rate from $40 \%$ of La(III) at $\mathrm{pH} 4$ to $85 \%$ at $\mathrm{pH} 5$ and $99.60 \%$ at $\mathrm{pH}$. This study reported the best sorption rate in the literature. Finally, the material with the highest maximum adsorption capacity (qm) of REEs reported in the literature to date was oxide and phosphorous functionalized nanoporous carbon with $344.6 \mathrm{mg} / \mathrm{g}$ of Dy achieved [121]; and, the best maximum adsorption capacity by an activated carbon was BETADHBA functionalized activated carbon (AC-BETADHBA) with $144.80 \mathrm{mg} / \mathrm{g}$ for La(III) [120].

\section{Conclusions Remarks and Perspectives}

Technology has never been so much dependent on electronic devices as it is today, which means a strong REEs dependency. Electronic devices become obsolete too quickly generating great amounts of e-waste annually, creating the need for a strategy to deal with this type of waste material. the incorrect treatment and storage of e-waste can cause serious damage to the environment with a result of REEs or even more toxic metals (such as $\mathrm{Hg}$ and $\mathrm{Pb}$ ) in aquatic environments. It is hence necessary to create and promote the recycling of e-waste.

There are several techniques to the recovery of rare earth elements, however, the most developed techniques are very harmful to the environment. New, greener and more efficient methods are needed. Carbon-based nanocomposites have been increasingly used for the recovery of metals, namely rare earth, due to their satisfactory physical and chemical properties, such as large surface area and a large number of oxygen groups to sorption. In addition, it is possible to incorporate functionalization in their defects that allow to improve the sorption efficiency or to provide them additional properties, such as magnetite, which make easy to remove the material from the solution by application of an external magnetic field. Carbon-based materials reported in the literature as being good sorbents were groups in this review in three categories: Graphene-based materials, carbon nanotubes, and other carbon materials that include activated carbon, fullerene, C-Dots, carbon black, mesoporous carbon, and carbon nanofibers. REE removal efficiency reported for those materials is 
highly variable, depending on key factors, such as $\mathrm{pH}$ of the solution, the mass of the sorbent, and time of contact between the contaminated solution and the sorbent. Only a few studies have tested the effect of competitive ions in solution on the REE sorption efficiency. The influence of ionic strength was almost neglected in the works published so far. Furthermore, almost all the experiments were carried out in Milli-Q water, with non-realistic concentrations and high doses of sorbent.

This review intended to summarize the progress on the thematic of REE removal by carbon-based materials, and to identify possible gaps. To prove the advantages of using carbon-based nanomaterials for REEs recovery from real industrial wastewaters and/or from end-of-life products a long and prosper way needs to be done. Tests with multi-element contaminated solutions, complexed situations with solutions of different ionic strengths and $\mathrm{pH}$, and approaches to realistic conditions are recommended.

Funding: This work is funded by national funds (OE), through FCT—Fundação para a Ciência e a Tecnologia, I.P., in the scope of the framework contract foreseen in the numbers 4, 5 and 6 of the article 23, of the Decree-Law 57/2016, of August 29, changed by Law 57/2017, of July 19; and the University of Aveiro, FCT/MEC for the financial support to CESAM, CICECO and CIIMAR [UID/AMB/50017/2013; UID/CTM/50011/2013; UID/Multi/04423/2013; UID/Multi/04423/2019], through national funds and, where applicable, co-financed by the FEDER, within the PT2020 Partnership Agreement.

Conflicts of Interest: The authors declare no conflict of interest.

\section{References}

1. Cobelo-García, A.; Filella, M.; Croot, P.; Frazzoli, C.; Du Laing, G.; Ospina-Alvarez, N.; Rauch, S.; Salaun, P.; Schäfer, J.; Zimmermann, S. COST action TD1407: Network on technology-critical elements (NOTICE)-from environmental processes to human health threats. Environ. Sci. Pollut. Res. 2015, 22, 15188-15194. [CrossRef] [PubMed]

2. Environmental Law Alliance Worldwide Overview of Mining and its Impacts. In Guidebook for Evaluating Mining Project EIAs; Environmental Law Alliance Worldwide: Eugene, OR, USA, 2014; pp. 3-18.

3. Rim, K.T.; Koo, K.H.; Park, J.S. Toxicological Evaluations of Rare Earths and Their Health Impacts to Workers: A Literature Review. Saf. Health Work 2013, 4, 12-26. [CrossRef] [PubMed]

4. Rim, K.-T. Effects of rare earth elements on the environment and human health: A literature review. Toxicol. Environ. Health Sci. 2016, 8, 189-200. [CrossRef]

5. Yang, L.; Wang, X.; Nie, H.; Shao, L.; Wang, G.; Liu, Y. Residual levels of rare earth elements in freshwater and marine fish and their health risk assessment from Shandong, China. Mar. Pollut. Bull. 2016, 107, 393-397. [CrossRef] [PubMed]

6. Pagano, G.; Aliberti, F.; Guida, M.; Oral, R.; Siciliano, A.; Trifuoggi, M.; Tommasi, F. Rare earth elements in human and animal health: State of art and research priorities. Environ. Res. 2015, 142, 215-220. [CrossRef]

7. Gonzalez, V.; Vignati, D.A.L.; Leyval, C.; Giamberini, L. Environmental fate and ecotoxicity of lanthanides: Are they a uniform group beyond chemistry? Environ. Int. 2014, 71, 148-157. [CrossRef]

8. Meryem, B.; Ji, H.; Gao, Y.; Ding, H.; Li, C. Distribution of rare earth elements in agricultural soil and human body (scalp hair and urine) near smelting and mining areas of Hezhang, China. J. Rare Earths 2016, 34, 1156-1167. [CrossRef]

9. Hao, Z.; Li, Y.; Li, H.; Wei, B.; Liao, X.; Liang, T.; Yu, J. Levels of rare earth elements, heavy metals and uranium in a population living in Baiyun Obo, Inner Mongolia, China: A pilot study. Chemosphere 2015, 128, 161-170. [CrossRef]

10. Wei, B.; Li, Y.; Li, H.; Yu, J.; Ye, B.; Liang, T. Rare earth elements in human hair from a mining area of China. Ecotoxicol. Environ. Saf. 2013, 96, 118-123. [CrossRef]

11. Atibu, E.K.; Devarajan, N.; Laffite, A.; Giuliani, G.; Salumu, J.A.; Muteb, R.C.; Mulaji, C.K.; Otamonga, J.P.; Elongo, V.; Mpiana, P.T.; et al. Assessment of trace metal and rare earth elements contamination in rivers around abandoned and active mine areas. The case of Lubumbashi River and Tshamilemba Canal, Katanga, Democratic Republic of the Congo. Chem. Geochem. 2016, 76, 353-362. [CrossRef]

12. Zhuang, M.; Zhao, J.; Li, S.; Liu, D.; Wang, K.; Xiao, P.; Yu, L.; Jiang, Y.; Song, J.; Zhou, J.; et al. Concentrations and health risk assessment of rare earth elements in vegetables from mining area in Shandong, China. Chemosphere 2016, 168, 578-582. [CrossRef] 
13. Kulaksiz, S.; Bau, M. Anthropogenic dissolved and colloid/nanoparticle-bound samarium, lanthanum and gadolinium in the Rhine River and the impending destruction of the natural rare earth element distribution in rivers. Earth Planet. Sci. Lett. 2013, 362, 43-50. [CrossRef]

14. Hatje, V.; Bruland, K.W.; Flegal, A.R. Determination of rare earth elements after pre-concentration using NOBIAS-chelate PA- $1{ }^{\circledR}$ resin: Method development and application in the San Francisco Bay plume. Mar. Chem. 2014, 160, 34-41. [CrossRef]

15. Zaimes, G.G.; Hubler, B.J.; Wang, S.; Khanna, V. Environmental Life Cycle Perspective on Rare Earth Oxide Production. ACS Sustain. Chem. Eng. 2015, 3, 237-244. [CrossRef]

16. Tansel, B. From electronic consumer products to e-wastes: Global outlook, waste quantities, recycling challenges. Environ. Int. 2017, 98, 35-45. [CrossRef]

17. Hobohm, J.; Kuchta, K. Innovative Recovery Strategies of Rare Earth and Other Critical Metals from Electric and Electronic Waste; Sociedad Española de Mineralogía: Huelva, Spain, 2015.

18. Baldé, C.P.; Forti, V.; Gray, V.; Kuehr, R.; Stegmann, P. The Global E-Waste Monitor 2017; United Nations University (UNU): Bonn, Germany; International Telecommunication Union (ITU): Geneva, Switzerland; International Solid Waste Association (ISWA): Vienna, Austria, 2017.

19. Tsamis, A.; Coyne, M. Recovery of Rare Earths from Electronic Wastes: An Opportunity for High-Tech SMEs; Centre for Strategy and Evaluation Services LLP: Brussels, Belgium, 2015.

20. Directorate General Enterprise and Industry EU Critical Raw Materials Profiles; European Commission: Brussels, Belgium, 2014; pp. 77-85.

21. Zepf, V. Rare Earth Elements; Springer Science \& Business Media: Berlin, Germany, 2013; ISBN 978-3-642-35457-1.

22. European Rare Earths Competency Network (ERECON). Strengthening the European Rare Earths Supply-Chain Challenges and Policy Options; European Comission: Brussels, Belgium, 2014.

23. Royen, H.; Fortkamp, U. Rare Earth Elements_Purification, Separation and Recycling; Environmental Research Institute: Stockholm, Sweden, 2016.

24. Dutta, T.; Kim, K.H.; Uchimiya, M.; Kwon, E.E.; Jeon, B.H.; Deep, A.; Yun, S.T. Global demand for rare earth resources and strategies for green mining. Environ. Res. 2016, 150, 182-190. [CrossRef]

25. Shriver, D.; Weller, M.; Overton, T.; Rourke, J.; Armstrong, F. Inorganic Chemistry; W. H. Freeman and Company: New York, NY, USA, 2014; ISBN 978-1-4292-9906-0.

26. Huang, C. Rare Earth Coordination Chemistry: Fundamentals and Applications; John Wiley \& Sons: Hoboken, NJ, USA, 2010; ISBN 978-0-470-82485-6.

27. Series, S. Spectroscopic Properties of Rare Earths in Optical Materials; Liu, G., Jacquier, B., Eds.; Springer Science \& Business Media: Berlin, Germany, 2005.

28. Binnemans, K.; Jones, P.T.; Blanpain, B.; Van Gerven, T.; Yang, Y.; Walton, A.; Burchert, M. Recycling of Rare Earth: A Critical Review. J. Clean. Prod. 2013, 51, 1-22. [CrossRef]

29. Ruiz-Mercado, G.J.; Gonzalez, M.A.; Smith, R.L.; Meyer, D.E. A conceptual chemical process for the recycling of Ce, Eu, and Y from LED flat panel displays. Resour. Conserv. Recycl. 2017, 126, 42-49. [CrossRef]

30. Yang, Y.; Walton, A.; Sheridan, R.; Güth, K.; Gauß, R.; Gutfleisch, O.; Buchert, M.; Steenari, B.-M.; Van Gerven, T.; Jones, P.T.; et al. REE Recovery from End-of-Life NdFeB Permanent Magnet Scrap: A Critical Review. J. Sustain. Metall. 2017, 3, 122-149. [CrossRef]

31. Abrahami, S.T.; Xiao, Y.; Yang, Y. Rare-earth elements recovery from post-consumer hard-disc drives. Miner. Process. Extr. Metall. 2015, 124, 106-115. [CrossRef]

32. München, D.D.; Veit, H.M. Neodymium as the main feature of permanent magnets from hard disk drives (HDDs). Waste Manag. 2017, 61, 372-376. [CrossRef]

33. Firdaus, M.; Rhamdhani, M.A.; Durandet, Y.; Rankin, W.J.; McGregor, K. Review of High-Temperature Recovery of Rare Earth (Nd/Dy) from Magnet Waste. J. Sustain. Metall. 2016, 2, 276-295. [CrossRef]

34. Yoon, H.-S.S.; Kim, C.-J.J.; Chung, K.-W.W.; Kim, S.-D.D.; Lee, J.-Y.Y.; Kumar, J.R. Solvent extraction, separation and recovery of dysprosium (Dy) and neodymium $(\mathrm{Nd})$ from aqueous solutions: Waste recycling strategies for permanent magnet processing. Hydrometallurgy 2016, 165, 27-43. [CrossRef]

35. Binnemans, K.; Jones, P.T. Perspectives for the recovery of rare earths from end-of-life fluorescent lamps. J. Rare Earths 2014, 32, 195-200. [CrossRef]

36. Tan, Q.; Li, J.; Zeng, X. Rare Earth Elements Recovery from Waste Fluorescent Lamps: A Review. Crit. Rev. Environ. Sci. Technol. 2015, 45, 749-776. [CrossRef] 
37. Wu, Y.; Yin, X.; Zhang, Q.; Wang, W.; Mu, X. The recycling of rare earths from waste tricolor phosphors in fluorescent lamps: A review of processes and technologies. Resour. Conserv. Recycl. 2014, 88, 21-31. [CrossRef]

38. Pyrzynska, K.; Kubiak, A.; Wysocka, I. Application of solid phase extraction procedures for rare earth elements determination in environmental samples. Talanta 2016, 154, 15-22. [CrossRef] [PubMed]

39. Liang, T.; Li, K.; Wang, L. State of rare earth elements in different environmental components in mining areas of China. Environ. Monit. Assess. 2014, 186, 1499-1513. [CrossRef]

40. Innocenzi, V.; Ippolito, N.M.; De Michelis, I.; Prisciandaro, M.; Medici, F.; Vegliò, F. A review of the processes and lab-scale techniques for the treatment of spent rechargeable NiMH batteries. J. Power Sources 2017, 362, 202-218. [CrossRef]

41. Lister, T.E.; Wang, P.; Anderko, A. Recovery of critical and value metals from mobile electronics enabled by electrochemical processing. Hydrometallurgy 2014, 149, 228-237. [CrossRef]

42. Kim, D.; Powell, L.E.; Delmau, L.H.; Peterson, E.S.; Herchenroeder, J.; Bhave, R.R. Selective Extraction of Rare Earth Elements from Permanent Magnet Scraps with Membrane Solvent Extraction. Environ. Sci. Technol. 2015, 49, 9452-9459. [CrossRef] [PubMed]

43. Sun, Z.; Xiao, Y.; Agterhuis, H.; Sietsma, J.; Yang, Y. Recycling of metals from urban mines-A strategic evaluation. J. Clean. Prod. 2016, 112, 2977-2987. [CrossRef]

44. Itoh, H. The recent trend of e-waste recycling and rare metal recovery in Japan. Wit Trans. Ecol. Environ. 2014, 180, 3-14.

45. Kaya, M. Recovery of metals and nonmetals from electronic waste by physical and chemical recycling processes. Waste Manag. 2016, 57, 64-90. [CrossRef]

46. Haque, N.; Hughes, A.; Lim, S.; Vernon, C. Rare Earth Elements: Overview of Mining, Mineralogy, Uses, Sustainability and Environmental Impact. Resources 2014, 3, 614-635. [CrossRef]

47. Hidayah, N.N.; Abidin, S.Z. The evolution of mineral processing in extraction of rare earth elements using solid-liquid extraction over liquid-liquid extraction: A review. Miner. Eng. 2017, 112, 103-113. [CrossRef]

48. Zhu, L.L.; Guo, L.; Zhang, Z.J.; Chen, J.; Zhang, S.M. The Preparation of Supported Ionic Liquids (SILs) and Their Application in Rare Metals Separation. Sci. China Chem. 2012, 55, 1479-1487. [CrossRef]

49. Xiao, S.; Yang, J.; Ji, C.; Jiu, M. Solvent impregnated resin prepared using task-specific ionic liquids for rare earth separation. J. Rare Earths 2009, 27, 932-936.

50. Ferella, F.; Innocenzi, V.; Maggiore, F. Oil refining spent catalysts: A review of possible recycling technologies. Resour. Conserv. Recycl. 2016, 108, 10-20. [CrossRef]

51. Abhilash, S.S.; Meshram, P.; Pandey, B.D. Metallurgical processes for the recovery and recycling of lanthanum from various resources-A review. Hydrometallurgy 2016, 160, 47-59.

52. Meshram, P.; Pandey, B.D.; Mankhand, T.R. Process optimization and kinetics for leaching of rare earth metals from the spent Ni-metal hydride batteries. Waste Manag. 2016, 51, 196-203. [CrossRef]

53. Duclos, L.; Svecova, L.; Laforest, V.; Mandil, G.; Thivel, P.X. Process development and optimization for platinum recovery from PEM fuel cell catalyst. Hydrometallurgy 2016, 160, 79-89. [CrossRef]

54. Bian, Y.; Guo, S.; Jiang, L.; Liu, J.; Tang, K.; Ding, W. Recovery of Rare Earth Elements from NdFeB Magnet by VIM-HMS Method. ACS Sustain. Chem. Eng. 2016, 4, 810-818. [CrossRef]

55. Bandara, H.M.D.; Field, K.D.; Emmert, M.H. Rare earth recovery from end-of-life motors employing green chemistry design principles. Green Chem. 2016, 18, 753-759. [CrossRef]

56. Dupont, D.; Binnemans, K. Rare-earth recycling using a functionalized ionic liquid for the selective dissolution and revalorization of $\mathrm{Y}_{2} \mathrm{O}_{3}: \mathrm{Eu}^{3+}$ from lamp phosphor waste. Green Chem. 2015, 17, 856-868. [CrossRef]

57. Tunsu, C.; Petranikova, M.; Gergorić, M.; Ekberg, C.; Retegan, T. Reclaiming rare earth elements from end-of-life products: A review of the perspectives for urban mining using hydrometallurgical unit operations. Hydrometallurgy 2015, 156, 239-258. [CrossRef]

58. Tan, Q.; Deng, C.; Li, J. Innovative Application of Mechanical Activation for Rare Earth Elements Recovering: Process Optimization and Mechanism Exploration. Sci. Rep. 2016, 6, 19961-19970. [CrossRef]

59. Fisher, A.; Kara, D. Determination of rare earth elements in natural water samples-A review of sample separation, preconcentration and direct methodologies. Anal. Chim. Acta 2016, 935, 1-29. [CrossRef]

60. Cao, W.; Hu, S.-S.; Ye, L.-H.; Cao, J.; Xu, J.-J.; Pang, X.-Q. Trace-chitosan-wrapped multi-walled carbon nanotubes as a new sorbent in dispersive micro solid-phase extraction to determine phenolic compounds. J. Chromatogr. A 2015, 1390, 13-21. [CrossRef] 
61. Giakisikli, G.; Anthemidis, A.N. Magnetic materials as sorbents for metal/metalloid preconcentration and/or separation. A review. Anal. Chim. Acta 2013, 789, 1-16. [CrossRef] [PubMed]

62. Ghazaghi, M.; Mousavi, H.Z.; Rashidi, A.M.; Shirkhanloo, H.; Rahighi, R. Graphene-silica hybrid in efficient preconcentration of heavy metal ions via novel single-step method of moderate centrifugation-assisted dispersive micro solid phase extraction. Talanta 2016, 150, 476-484. [CrossRef]

63. Hu, Y.; Pan, J.; Zhang, K.; Lian, H.; Li, G. Novel applications of molecularly-imprinted polymers in sample preparation. Trends Anal. Chem. 2013, 43, 37-52. [CrossRef]

64. Branger, C.; Meouche, W.; Margaillan, A. Recent advances on ion-imprinted polymers. React. Funct. Polym. 2013, 73, 859-875. [CrossRef]

65. Dhand, V.; Rhee, K.Y.; Ju Kim, H.; Ho Jung, D.; Dhand, V.; Rhee, K.Y.; Ju Kim, H.; Ho Jung, D. A Comprehensive Review of Graphene Nanocomposites: Research Status and Trends. J. Nanomater. 2013, 2013, 763953-763966. [CrossRef]

66. Pastrana-Martínez, L.M.; Morales-Torres, S.; Gomes, H.T.; Silva, A.M.T. Nanotubos e grafeno: Os primos mais jovens na família do carbono! Química 2013, 128, 21-27.

67. Yu, S.; Wang, X.X.; Tan, X.; Wang, X.X. Sorption of radionuclides from aqueous systems onto graphene oxide-based materials: A review. Inorg. Chem. Front. 2015, 2, 593-612. [CrossRef]

68. Guerrero-Contreras, J.; Caballero-Briones, F. Graphene oxide powders with different oxidation degree, prepared by synthesis variations of the Hummers method. Mater. Chem. Phys. J. 2015, 153, 209-220. [CrossRef]

69. Katsnelson, M.I. Graphene: Carbon in two dimensions. Mater. Today 2007, 10, 20-27. [CrossRef]

70. Valles, C.; Drummond, C.; Saadaoui, H.; Furtado, C.A.; He, M.; Roubeau, O.; Ortolani, L.; Monthioux, M.; $\mathrm{Pe}, \mathrm{A}$. Solutions of Negatively Charged Graphene Sheets and Ribbons Solutions of Negatively Charged Graphene Sheets and Ribbons. J. Am. Chem. Soc. 2008, 130, 15802-15804. [CrossRef]

71. Lavin-Lopez, M.D.P.; Romero, A.; Garrido, J.; Sanchez-Silva, L.; Valverde, J.L. Influence of different improved hummers method modifications on the characteristics of graphite oxide in order to make a more easily scalable method. Ind. Eng. Chem. Res. 2016, 55, 12836-12847. [CrossRef]

72. Paredes, J.I.; Villar-Rodil, S.; Martínez-Alonso, A.; Tascón, J.M.D. Graphene Oxide Dispersions in Organic Solvents. Langmuir 2008, 24, 10560-10564. [CrossRef]

73. Kovtyukhova, N.I. Layer-by-layer assembly of ultrathin composite films from micron-sized graphite oxide sheets and polycations. Chem. Mater. 1999, 11,771-778. [CrossRef]

74. Yu, Y.-Y.; Kang, B.H.; Lee, Y.D.; Lee, S.B.; Ju, B.-K. Effect of fluorine plasma treatment with chemically reduced grapheneoxide thin films as hole transport layer in organic solar cells. Appl. Surf. Sci. 2013, 287, 91-96. [CrossRef]

75. Nikolakopoulou, A.; Tasis, D.; Sygellou, L.; Dracopoulos, V.; Galiotis, C.; Lianos, P. Study of the thermal reduction of graphene oxide and of its application as electrocatalyst in quasi-solid state dye-sensitized solarcells in combination with PEDOT. Electrochim. Acta 2013, 111, 698-706. [CrossRef]

76. Ma, C.; Liu, W.; Shi, M.; Lang, X.; Chu, Y.; Chen, Z.; Zhao, D.; Lin, W.; Hardacre, C. Low loading platinum nanoparticles on reduced graphene oxide-supported tungsten carbide crystallites as a highly active electrocatalyst for methanol oxidation. Electrochim. Acta 2013, 114, 133-141. [CrossRef]

77. Marcano, D.C.; Kosynkin, D.V.; Berlin, J.M.; Sinitskii, A.; Sun, Z.; Slesarev, A.; Alemany, L.B.; Lu, W.; Tour, J.M. Improved Synthesis of Graphene Oxide. ACS Nano 2010, 4, 4806-4814. [CrossRef]

78. Li, J.; Zeng, X.; Ren, T.; van der Heide, E. The Preparation of Graphene Oxide and Its Derivatives and Their Application in Bio-Tribological Systems. Lubricants 2014, 2, 137-161. [CrossRef]

79. Dreyer, D.R.; Park, S.; Bielawski, C.W.; Ruoff, R.S. The chemistry of graphene oxide. Chem. Soc. Rev. 2010, 39, 228-240. [CrossRef]

80. Chung, D.D.L. A review of exfoliated graphite. J. Mater. Sci. 2016, 51, 554-568. [CrossRef]

81. Acik, M.; Chabal, Y.J. A Review on Thermal Exfoliation of Graphene Oxide. J. Mater. Sci. Res. 2012, 2, 101-112.

82. Zhao, F.; Repo, E.; Meng, Y.; Wang, X.; Yin, D.; Sillanpää, M. An EDTA-b-cyclodextrin material for the adsorption of rare earth elements and its application in preconcentration of rare earth elements in seawater. J. Colloid Interface Sci. 2016, 465, 215-224. [CrossRef]

83. Dupont, D.; Brullot, W.; Bloemen, M.; Verbiest, T.; Binnemans, K. Selective Uptake of Rare Earths from Aqueous Solutions by EDTA- Functionalized Magnetic and Nonmagnetic Nanoparticles. ACS Appl. Mater. Interfaces 2014, 6, 4980-4988. [CrossRef] 
84. Noack, C.W.; Perkins, K.M.; Callura, J.C.; Washburn, N.R.; Dzombak, D.A.; Karamalidis, A.K. Effects of ligand chemistry and geometry on rare earth element partitioning from saline solutions to functionalized adsorbents. ACS Sustain. Chem. Eng. 2016, 4, 6115-6124. [CrossRef]

85. Ogata, T.; Narita, H.; Tanaka, M. Adsorption mechanism of rare earth elements by adsorbents with diglycolarnic acid ligands. Hydrometallurgy 2016, 163, 156-160. [CrossRef]

86. Juère, E.; Florek, J.; Larivière, D.; Kim, K.; Kleitz, F. Support effects in rare earth element separation using diglycolamide-functionalized mesoporous silica. New J. Chem. 2016, 40, 4325-4334. [CrossRef]

87. Sengupta, A.; Deb, A.K.S.; Dasgupta, K.; Adyaa, V.C.; Ali, S.M. Diglycolamic acid-functionalized multiwalled carbon nanotubes as a highly efficient sorbent for f-block elements: Experimental and theoretical investigations. New J. Chem. 2017, 41, 4531-4545. [CrossRef]

88. Yang, S.; Zong, P.; Ren, X.; Wang, Q.; Wang, X. Rapid and Highly E ffi cient Preconcentration of Eu(III) by Core-Shell Structured $\mathrm{Fe}_{3} \mathrm{O}_{4} @ H u m i c$ Acid Magnetic Nanoparticles. ACS Appl. Mater. Interfaces 2012, 4, 6891-6900. [CrossRef]

89. Huang, C.; Hu, B. Silica-coated magnetic nanoparticles modified with $\gamma$-mercaptopropyltrimethoxysilane for fast and selective solid phase extraction of trace amounts of $\mathrm{Cd}, \mathrm{Cu}, \mathrm{Hg}$, and $\mathrm{Pb}$ in environmental and biological samples prior to their determination by inductively co. Spectrochim. Acta Part B Spectrosc. 2008, 63, 437-444. [CrossRef]

90. Sun, Y.; Shao, D.; Chen, C.; Yang, S.; Wang, X. Highly efficient enrichment of radionuclides on graphene oxide-supported polyaniline. Environ. Sci. Technol. 2013, 47, 9904-9910. [CrossRef]

91. Li, D.; Zhang, B.; Xuan, F. The sorption of Eu(III) from aqueous solutions by magnetic graphene oxides: A combined experimental and modeling studies. J. Mol. Liq. 2015, 211, 203-209. [CrossRef]

92. Chen, W.; Wang, L.; Zhuo, M.; Liu, Y.; Wang, Y.; Li, Y. Facile and highly efficient removal of trace Gd(III) by adsorption of colloidal graphene oxide suspensions sealed in dialysis bag. J. Hazard. Mater. 2014, 279, 546-553. [CrossRef]

93. Chen, W.; Wang, L.; Zhuo, M.; Wang, Y.; Fu, S.; Li, Y.; Wu, S. Reusable colloidal graphene oxide suspensions combined with dialysis bags for recovery of trace $\mathrm{Y}(\mathrm{III})$ from aqueous solutions. RSC Adv. 2014, 4, 58778-58787. [CrossRef]

94. Ashour, R.M.; Abdelhamid, H.N.; Abdel-Magied, A.F.; Abdel-Khalek, A.A.; Ali, M.M.; Uheida, A.; Muhammed, M.; Zou, X.; Dutta, J. Rare Earth Ions Adsorption onto Graphene Oxide Nanosheets. Solvent Extr. Ion Exch. 2017, 35, 91-103. [CrossRef]

95. Su, S.; Chen, B.; He, M.; Hun, B.; Xiao, Z.; Hu, B.; Xiao, Z. Determination of trace/ultratrace rare earth elements in environmental samples by ICP-MS after magnetic solid phase extraction with $\mathrm{Fe}_{3} \mathrm{O}_{4} @ \mathrm{SiO}_{2} @$ polyaniline-graphene oxide composite. Talanta 2014, 119, 458-466. [CrossRef]

96. Fakhri, H.; Mahjoub, A.R.; Aghayan, H. Effective removal of methylene blue and cerium by a novel pair set of heteropoly acids based functionalized graphene oxide: Adsorption and photocatalytic study. Chem. Eng. Res. Des. 2017, 120, 303-315. [CrossRef]

97. Farzin, L.; Shamsipur, M.; Shanehsaz, M.; Sheibani, S. A new approach to extraction and preconcentration of $\mathrm{Ce}(\mathrm{III})$ from aqueous solutions using magnetic reduced graphene oxide decorated with thioglycolic-acid-capped CdTe QDs. Int. J. Environ. Anal. Chem. 2017, 97, 854-867. [CrossRef]

98. Kilian, K.; Pyrzyńska, K.; Peggier, M. Comparative Study of Sc(III) Sorption onto Carbon-based Materials. Solvent Extr. Ion Exch. 2017, 35, 450-459. [CrossRef]

99. Xie, Y.; Helvenston, E.M.; Shuller-Nickles, L.C.; Powell, B.A. Surface Complexation Modeling of Eu(III) and U(VI) Interactions with Graphene Oxide. Environ. Sci. Technol. 2016, 50, 1821-1827. [CrossRef]

100. Yao, T.; Xiao, Y.; Wu, X.; Guo, C.; Zhao, Y.; Chen, X. Adsorption of Eu(III) on sulfonated graphene oxide: Combined macroscopic and modeling techniques. J. Mol. Liq. 2016, 215, 443-448. [CrossRef]

101. Sun, Y.; Wang, Q.; Chen, C.; Tan, X.; Wang, X. Interaction between Eu(III) and Graphene Oxide Nanosheets Investigated by Batch and Extended X-ray Absorption Fine Structure Spectroscopy and by Modeling Techniques. Environ. Sci. Technol. 2012, 46, 6020-6027. [CrossRef]

102. Li, C.; Huang, Y.; Lin, Z. Fabrication of titanium phosphate@graphene oxide nanocomposite and its super performance on $\mathrm{Eu}^{3+}$ recycling. J. Mater. Chem. A 2014, 2, 14979-14985. [CrossRef]

103. Lasorsa, C.; Perez, M.; Lerner, B.; Toper, I.; Versaci, R.; Lamagna, A.; Boselli, A. Optimization of a Carbon Nanotubes Manufacturing Process by the Technique of PECVD. Procedia Mater. Sci. 2012, 1, 558-563. [CrossRef] 
104. Bierdel, M.; Buchholz, S.; Michele, V.; Mleczko, L.; Rudolf, R.; Voetz, M.; Wolf, A. Industrial production of multiwalled carbon nanotubes. Phys. Status Solidi 2007, 244, 3939-3943. [CrossRef]

105. Yadav, K.K.; Dasgupta, K.; Singh, D.K.; Anitha, M.; Varshney, L.; Singh, H. Solvent impregnated carbon nanotube embedded polymeric composite beads: An environment benign approach for the separation of rare earths. Sep. Purif. Technol. 2015, 143, 115-124. [CrossRef]

106. Behdani, F.N.; Rafsanjani, A.T.; Torab-Mostaedi, M.; Mohammadpour, S.M.A.K. Adsorption ability of oxidized multiwalled carbon nanotubes towards aqueous Ce(III) and Sm(III). Korean J. Chem. Eng. 2013, 30, 448-455. [CrossRef]

107. Koochaki-Mohammadpour, S.M.A.; Torab-Mostaedi, M.; Talebizadeh-Rafsanjani, A.; Naderi-Behdani, F. Adsorption Isotherm, Kinetic, Thermodynamic, and Desorption Studies of Lanthanum and Dysprosium on Oxidized Multiwalled Carbon Nanotubes. J. Dispers. Sci. Technol. 2014, 35, 244-254. [CrossRef]

108. Li, K.; Gao, Q.; Yadavalli, G.; Shen, X.; Lei, H.; Han, B.; Xia, K.; Zhou, C. Selective Adsorption of Gd ${ }^{3+}$ on $^{2}$ a Magnetically Retrievable Imprinted Chitosan/Carbon Nanotube Composite with High Capacity. ACS Appl. Mater. Interfaces 2015, 7, 21047-21055. [CrossRef]

109. Chen, C.L.; Wang, X.K.; Nagatsu, M. Europium Adsorption on Multiwall Carbon Nanotube/Iron Oxide Magnetic Composite in the Presence of Polyacrylic Acid. Environ. Sci. Technol. 2009, 43, 2362-2367. [CrossRef]

110. Fan, Q.H.; Shao, D.D.; Hu, J.; Chen, C.L.; Wu, W.S.; Wang, X.K. Adsorption of humic acid and Eu(III) to multi-walled carbon nanotubes: Effect of $\mathrm{pH}$, ionic strength and counterion effect. Radiochim. Acta 2009, 97, 141-148. [CrossRef]

111. Chen, C.; Hu, J.; Xu, D.; Tan, X.; Meng, Y.; Wang, X. Surface complexation modeling of Sr(II) and Eu(III) adsorption onto oxidized multiwall carbon nanotubes. J. Colloid Interface Sci. 2008, 323, 33-41. [CrossRef]

112. Tong, S.; Zhao, S.; Zhou, W.; Li, R.; Jia, Q. Modification of multi-walled carbon nanotubes with tannic acid for the adsorption of La, Tb and Lu ions. Microchim. Acta 2011, 174, 257-264. [CrossRef]

113. Kammerer, D.R.; Kammerer, J.; Carle, R. Resin Adsorption and Ion Exchange to Recover and Fractionate Polyphenols. In Polyphenols in Plants; Elsevier: Amsterdam, The Netherlands, 2014; pp. 219-230. ISBN 9780123979346.

114. Gupta, V.K. Suhas Application of low-cost adsorbents for dye removal-A review. J. Environ. Manag. 2009, 90, 2313-2342. [CrossRef]

115. Smith, Y.R.; Bhattacharyya, D.; Willhard, T.; Misra, M. Adsorption of aqueous rare earth elements using carbon black derived from recycled tires. Chem. Eng. J. 2016, 296, 102-111. [CrossRef]

116. Chen, S.; Xiao, M.; Lu, D.; Zhan, X. Carbon nanofibers as solid-phase extraction adsorbent for the preconcentration of trace rare earth elements and their determination by inductively coupled plasma mass spectrometry. Anal. Lett. 2007, 40, 2105-2115. [CrossRef]

117. Agrawal, Y.K. Poly( $\beta$-Styryl)-(1,2-Methanofullerene-C60)-61-Formo Hydroxamic Acid for the Solid Phase Extraction, Separation and Preconcentration of Rare Earth Elements. Fuller. Nanotub. Carbon Nanostruct. 2007, 15, 353-365. [CrossRef]

118. Chen, S.; Xiao, M.; Lu, D.; Zhan, X. Use of a microcolumn packed with modified carbon nanofibers coupled with inductively coupled plasma mass spectrometry for simultaneous on-line preconcentration and determination of trace rare earth elements in biological samples. Rapid Commun. Mass Spectrom. 2007, 21, 2524-2528. [CrossRef]

119. Gad, H.M.H.; Awwad, N.S. Factors affecting on the sorption/desorption of Eu (III) using activated carbon. Sep. Sci. Technol. 2007, 42, 3657-3680. [CrossRef]

120. Marwani, H.M.; Albishri, H.M.; Jalal, T.A.; Soliman, E.M. Study of isotherm and kinetic models of lanthanum adsorption on activated carbon loaded with recently synthesized Schiff's base. Arab. J. Chem. 2017, 10, 1032-1040. [CrossRef] 
121. Saha, D.; Akkoyunlu, S.D.; Thorpe, R.; Hensley, D.K.; Chen, J. Adsorptive recovery of neodymium and dysprosium in phosphorous functionalized nanoporous carbon. J. Environ. Chem. Eng. 2017, 5, 4684-4692. [CrossRef]

122. Perreault, L.L.; Giret, S.; Gagnon, M.; Florek, J.; Larivière, D.; Kleitz, F. Functionalization of Mesoporous Carbon Materials for Selective Separation of Lanthanides under Acidic Conditions. ACS Appl. Mater. Interfaces 2017, 9, 12003-12012. [CrossRef]

(C) 2019 by the authors. Licensee MDPI, Basel, Switzerland. This article is an open access article distributed under the terms and conditions of the Creative Commons Attribution (CC BY) license (http://creativecommons.org/licenses/by/4.0/). 